\title{
Computer Simulation of Low Frequency Vibration in Electrochemical Machining
}

\author{
Feng, Z.J, Lomeli, P., and Hung, N.P.

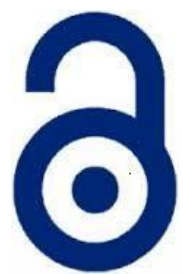 \\ Received: 08 September 2020 \\ Accepted: 14 December 2020 \\ Published: 30 January 2021 \\ Publisher: Deer Hill Publications \\ (c) 2021 The Author(s) \\ Creative Commons: CC BY 4.0
}

\begin{abstract}
This research studies how particles transport between low frequency vibrating electrodes during electrochemical machining (ECM). The ANSYS Fluent software was used to study the particle speed while the Star CCM+ software was utilized to study particle interactions during vibration-assisted ECM process. A series of simulations were conducted to calculate the particle average flushing speed. Collided particles either gained momentum or deflected their trajectories to accelerate in the flow of electrolyte. Simulation results showed that the highest average flushing speed of $0.4 \mathrm{~m} / \mathrm{s}$ was obtained at $40 \mathrm{~Hz}$ vibration frequency and $10 \mu \mathrm{m}$ vibration amplitude. Such higher flushing speed of particles improved machining depth (material removal rate) and produced a sharper machined profile. Experiment results confirmed that the maximum machining depth and minimum taper angle were obtained when vibrating the anodic workpiece at $40 \mathrm{~Hz}$ and $10 \mu \mathrm{m}$ amplitude. Machining depth and ECM material removal rate had a positive correlation with the average flushing speed. A sharper ECM'ed profile was achieved since the taper angle was favorably reduced at high average flushing speed.
\end{abstract}

Keywords: Low frequency vibration, Simulation, Pulsed current, Electrochemical machining, Particle flushing.

\section{INTRODUCTION}

Electrochemical machining (ECM), based on the principle of controlled anodic dissolution, has been used to fabricate complex shapes from an electrically conductive component. This is particularly useful to shape engineering alloys that are difficult to be machined such as tool steels, tungsten carbides and superalloys. This ECM process does not induce any thermal or mechanical residual stresses nor subsurface defects below a workpiece, generates no burr, has no tool wear, yet could achieve an excellent surface quality when the parameters are suitable for electrochemical polishing. Since we can eliminate secondary processes for deburring and stress relieving when applying ECM, this process would be a promising technique to machine/polish metallic materials if a decent material removal rate (MRR) can be achieved.

Ion transport mechanism affects the removal rate in ECM. The movement of ions is controlled by three mechanisms: migration, diffusion and convection [1]. A high MRR requires fast ion and by-product movement rates (i.e. by increasing one or all of the migration rate, diffusion rate and convection rate). Researchers have attempted to utilize different techniques to improve these transport rates with different approaches by:

- Applying a high voltage to increase migration rates [2-4]

- Applying pulsed current instead of using direct current [5-8]

- Increasing high electrolyte flow rates to increase diffusion rates [3,9]

- Vibrating of either workpiece or electrode at low vibration frequency to increase the convection rates $[8,10$ 14]

- Applying ultrasonic vibration of electrode or via electrolyte $[13,15,16]$.

Convection is the most significant factor that affects ion transport mechanism. The classical Faraday's law and published literature have shown that a higher voltage/current resulted in high MRR; however, the resulted byproducts and excessive heat must be removed, for example, with a costly electrolyte pumping system. An alternative solution is to incorporate pulsed current and vibration into ECM to improve the electrolyte flow while reducing its temperature. Researchers have attempted to vibrate either electrode or workpiece at different vibration frequency

Feng, Z.J.1, Lomeli, P. ${ }^{2}$, and Hung, N.P. ${ }^{\circledR} \otimes$

TTexas A\&M University, MS 3367, ETID, College Station, Texas 77843, USA

${ }^{2}$ Keysight Technologies, Santa Rosa, California, USA.

E-mail: hung@tamu.edu

Reference: Feng, Z.J., Lomeli, P., and Hung, N.P. (2021). Computer Simulation of Low Frequency Vibration in Electrochemical Machining. International Journal of Engineering Materials and Manufacture, 6(1), 1-21. 
and amplitude to enhance the process instead of installing an expensive pump for high volume electrolyte flow rate that might deflect a fragile or low compliance workpiece. Although vibration-assisted ECM has been studied experimentally, the mechanism on how low frequency vibration improves MMR is yet to be investigated. The objectives of this paper are to:

i) Simulate the flow of by-product in a horizontally vibrated ECM system.

ii) Study the by-product interaction between electrodes.

iii) Verify the simulation study with experimental data.

\section{LITERATURE REVIEW}

Many researchers have performed experimental investigation on the effect of vibration on ECM. In an ultrasonicassisted ECM system, controlled vibration of either the tool electrode or electrolyte to agitate the abrasives suspended in the electrolyte had shown to improve surface finish of the workpiece [16]. A study of the geometry and type of electrode that resulted in a well-polished surface $(0.7 \mu \mathrm{m} \mathrm{Ra})$ was reported and the effect of ultrasonic energy was acknowledged [17]. This energy was also responsible for the removal of debris from the machining zone and creation of optimal hydrodynamic conditions that affected the surface layers [18].

Hybridization ECM with low frequency tool vibration provided a positive and beneficial effect by changing the physical conditions in the inter-electrode gap (IEG). The variation of the gap pressure led to the removal of the sludge products and allowed renewal of the electrolyte in the machining gap. The reciprocal motion between the tool and the workpiece surface enhanced the circulation of the electrolyte through the interface to permit the use of higher current densities in order to improve the quality of the resultant surface and faster removal rate. In traditional vibration-assisted ECM the anode/cathode were vibrated in the vertical direction, thus the resulted by-products, that deposited on either electrode due to gravity, would hinder ion transport mechanism. A horizontal and vibrationassisted ECM was proposed as a remedial solution [6,16,19-21], in which a workpiece vibrated in the horizontal direction instead of the vertical direction to facilitate flushing of the resulted by-products.

For ECM and its variant processes, it is essential to estimate the volume of anode material removal during a specific time. The MRR is a function of current density distribution in the IEG where varying electrical conductivity of the electrolyte exists. Electrolyte velocity and pressure field in the IEC affected the gas bubble formation and temperature distribution, hence degraded the properties of electrolyte properties and current density [22]. As the consequence, any numerical simulation model would include mass, momentum, heat, electric charge and energy balance equations [23,24]. Due to the non-contact nature of the ECM process, it was essential to develop a simulation model to predict the anodic profile. The first electrode shape change simulation model was based on analytical techniques. An ECM tool design was suggested by using the "sine rule" [1]. This rule can be used to obtain an approximate shape but it failed when the tools had sharp discontinuities due to the neglection of stray current effects and the assumption of parallel flux lines. Other authors suggested to use an analytical direct computation for twodimensional (2D) ECM, represented the workpiece by Fourier's series and validated their models with experimental work [25], or utilizing finite element method for the 2D computation of MRR in ECM [26,27]. The latter model took the effects of simultaneous changes in the electrolyte flow speed and temperature rise into consideration.

Numerical simulation of three-dimensional (3D) electrode shape changes obtained during the ECM processes based on the "marker" method was also proposed [28]. A complex 3D structure was fabricated by pulsed electrochemical micromachining (PECMM) using ultrashort pulses; The effect of unsteady phenomena in electrical double layer on final anode shape also included in this study [29]. Numerical simulation of the ECM process included the temperature effects was studied in other investigations and the temperature distribution was found to have an influence on the shape of the anode [23,24]. For better accuracy and simplification of tool design, a small yet stable IEG (by reducing the nonuniformity of the electrolyte conductivity) was required. Commercial software package was also used to predict the final anode shape [30].

A review of mass transfer issues and other problems associated with the ECM process was published [31] and the numerical modeling of the ECM process considering the hydrodynamics involved in the process was also studied $[32,33]$. The final anode shapes resulting after the ECM using a triangular shaped cathode and curved surface were modeled in these studies. Another model was developed to predict the variation of gap in the ECM process using pulsed current with a stationary electrode and rotating workpiece. The model predicted the gap, evolution of anodic profile, and estimation of resulted surface roughness value [34]. Simulation of heat generation during ECM process and its effective dissipation using electrolyte flow was studied; it was found that a hollow cathode and pulse voltages effectively helped to control the heat generation [35].

Published literature did not cover the interaction of discrete particles between electrode gap and the effect of vibration frequency on particle flow in an electrolyte. The following sections describe details of two simulations using Fluent and Star CCM+ software. The simulation results are then compared with experimental and published data. 


\section{SIMULATION OF PARTICLE FLOW}

3.1 Governing Equations

A successful ECM process depends on the efficiency of debris flushing and effectiveness of fresh chemical replenishment to anodic surface. The motion can be modeled using Newton's second law of motion; the governing equations for translational motion of discrete particle $i$ with mass $m_{i}$ can be written as:

$$
m_{i} \frac{d \overrightarrow{v_{l}}}{d t}=\sum_{j} \overrightarrow{F_{l j}^{c}}+\sum_{k} \overrightarrow{F_{l k}^{n c}}+\overrightarrow{F_{l}^{f}}+\overrightarrow{F_{l}^{g}}
$$

Where,

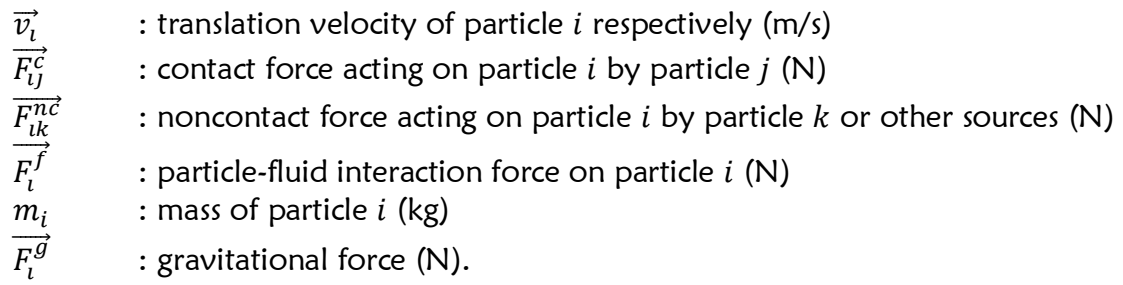

During an ECM process, a typical removal rate of an anode is $45.3 \mathrm{~mm}^{3} / \mathrm{min}$ which is much less than the electrolyte flow rate of $2.5 \mathrm{~L} / \mathrm{min}\left(2,500,000 \mathrm{~mm}^{3} / \mathrm{min}\right)$ [6]. It is assumed that by-product particle interaction is insignificant, so single particle instead of multiple particles can be used in simulation of debris flushing. Therefore, the contact force and non-contact forces between particles can be neglected, the equation (1) can be simplified to:

$$
m_{i} \frac{d \overrightarrow{v_{l}}}{d t}=\overrightarrow{F_{l}^{f}}+\overrightarrow{F_{l}^{g}}
$$

Once the forces in equation (2) are known, this equation can be readily solved numerically to determine the particle's trajectory and velocity.

\subsection{Particle-Fluid Interaction Forces}

In addition to the buoyance force, various particle-fluid interaction forces will be generated during the particles interact with surrounding fluid. For example, the translation of particle was driven by drag force and resisted by stagnant fluid. Thus, particle-fluid interaction forces could be considered [36]. Several forces can be implemented in discrete element method in computing fluid dynamics, for examples drag force, pressure gradient force, unsteady force, and lift forces $[37,38]$.

\subsubsection{Fluid-Particle Interaction Drag Force}

For an isolated sphere particle suspended in a fluid, the Newton's equation was used to determine the drag resistance force. The particle-fluid drag coefficient $C_{d}$ is dependent upon Reynold's number $R_{e}$ in addition to liquid properties. There are three regions: the Stoke's Law region, the transition region, and Newton's law region.

Two methods were used to determine the particle-fluid drag force. The first method based on empirical correlations for either bed expansion [39] or bed pressure drop experiment [40]. The other method based on numerical simulations at microscale, where the technique used the direct numerical simulation [41]. The latter method, although rational, was limited by the current computation capability. Numerical studies had been applied to relatively simple systems. A study that systematically investigated and quantified the differences among these correlations was published [42]; The results revealed that these correlations with similar predictive capability, although their accuracy may differ. In this study, the coefficient was adopted from another study [43], and the fluid-particle interaction drag force are defined as:

$$
\begin{gathered}
\overrightarrow{F_{d}}=m \frac{\overrightarrow{V_{F}}-\overrightarrow{V_{p}}}{\tau_{r}} \\
\tau_{r}=\frac{\rho_{p} d_{p}^{2}}{18 \mu} \frac{24}{C_{d} R_{e}} \\
R_{e} \equiv \frac{\rho_{F} d_{p}\left|\vec{V}_{p}-\overrightarrow{V_{F}}\right|}{\mu} \\
C_{d}=a_{1}+\frac{a_{2}}{R_{e}}+\frac{a_{3}}{R_{e}}
\end{gathered}
$$

Where,

$$
\begin{array}{ll}
\overrightarrow{F_{d}} & : \text { drag force }(\mathrm{N}) \\
\overrightarrow{V_{F}} & : \text { fluid phase velocity }(\mathrm{m} / \mathrm{s})
\end{array}
$$




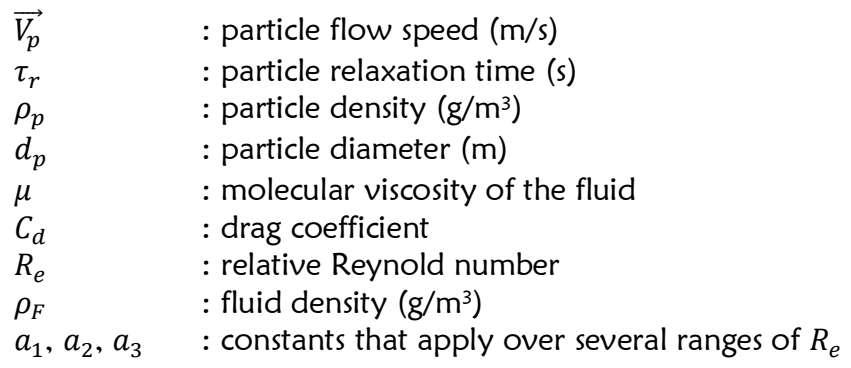

\subsection{Fluid-Particle Flow Modeling}

Simulations using complementary software were employed in this study. The ANSYS Fluent software was used in this study to simulate single particle flow while neglecting particle-particle interaction forces. The Star CCM+ software was used to simulate multiple particles flow which can capture the particle-particle interaction in a fluid-particle flow system.

In the discrete element method of computational fluid dynamics (CFD-DEM), the primary phase (fluid) flow was determined by the CFD on a computational cell scale and the second phase (particles) was obtained by solving Newton's equations of motion [44]. The governing equation for fluid was the Navier-Stoke equation which was the same as the two-fluid method (TFM). The CFD-DEM technique was used in this study because of its superior computational convenience and capability to capture the particle physics, such as, trajectories and velocities. In the CFD-DEM approach, the modeling of particles flow was at individual particle level and the modeling of fluid flow by CFD was at computation cell level. At each step, the DEM would give information, such as locations and velocities of individual particle, for the evaluation of porosity and volumetric fluid drag force in a computational cell. The CFD would then use these data to determine the fluid flow field which then yield the fluid drag forces acting on individual particles. Incorporation of the resulting forces into the DEM will produce information about the motion of individual particles for next time step. At each time step, the fluid-particle interaction forces on individual particles in a computational cell were calculated first, and then the values were added to produce the particle-fluid interaction force at the cell scale, as shown in following equations.

$$
\begin{gathered}
F_{\text {new }}=F_{\text {old }}+\alpha\left(F_{\text {calculated }}-F_{\text {old }}\right) \\
Q_{\text {new }}=Q_{\text {old }}+\alpha\left(Q_{\text {calculated }}-Q_{\text {old }}\right) \\
M_{\text {new }}=M_{\text {old }}+\alpha\left(M_{\text {calculated }}-M_{\text {old }}\right)
\end{gathered}
$$

Where,

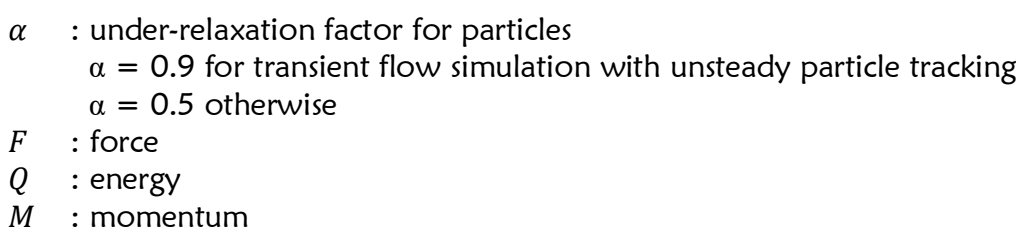

\subsection{Particle Flow Simulations in Interelectrode Gap}

This study utilized high strength low alloy (HSLA) steel in experiments to confirm the simulation trends. Since the major composition of HSLA steel is iron (97-99\%), during ECM process several possible reactions may occur at the workpiece and electrode. The reaction is the dissolution of iron at anode.

$$
\mathrm{Fe} \rightarrow \mathrm{Fe}^{2+}+2 e^{-}
$$

At the electrode, hydrogen and hydroxyl ions are produced:

$$
2 \mathrm{H}_{2} \mathrm{O}+2 e^{-} \rightarrow \mathrm{H}_{2} \uparrow+2 \mathrm{OH}^{-}
$$

Thus, the overall reaction of iron in ECM process is:

$$
\mathrm{Fe}+2 \mathrm{H}_{2} \mathrm{O} \rightarrow \mathrm{Fe}(\mathrm{OH})_{2}+\mathrm{H}_{2} \uparrow
$$

The ferrous hydroxide $\mathrm{Fe}(\mathrm{OH})_{2}$ may further react with water and oxygen to form ferric hydroxide $\mathrm{Fe}(\mathrm{OH})_{3}$.

$$
\mathrm{Fe}(\mathrm{OH})_{2}+2 \mathrm{H}_{2} \mathrm{O}+\mathrm{O}_{2} \rightarrow 4 \mathrm{Fe}(\mathrm{OH})_{3}
$$

In the ECM process, the anodic steel would form iron hydroxide by-products that need to be flushed away for effective process. Such by-product was assumed to be spherical particles with dimensions to be measured experimentally. The ANSYS Fluent was used to simulate how the single particle would move in vibration assisted 
pulsed ECM. While Star CCM+ was used to simulate how multiple particles would flow and interact in vibration assisted pulsed ECM. The effects of vibration frequency and vibration amplitude on particle average flushing speed are presented in the result section.

\subsubsection{Single Particle Simulation}

Figure 1 shows the horizontal tubular electrode and workpiece with origin at the tube center. The workpiece surface is on the vertical $y_{0}-z_{0}$ plane and is separated from the tubular electrode at a small interelectrode gap. Consider a byproduct particle $\mathrm{P}$ between the electrode and workpiece and its free-body diagram. The particle, forming an angle $\varphi$ with the horizontal axis, is subjected to gravity force, buoyance force, and drag force in flowing electrolyte. Due to the axisymmetric electrode, the drag force is in radial direction away from the tube center. The sum of forces in the radial direction is:

$$
F_{r}=F_{d}-\left(G-F_{b}\right) \sin \varphi
$$

Where,
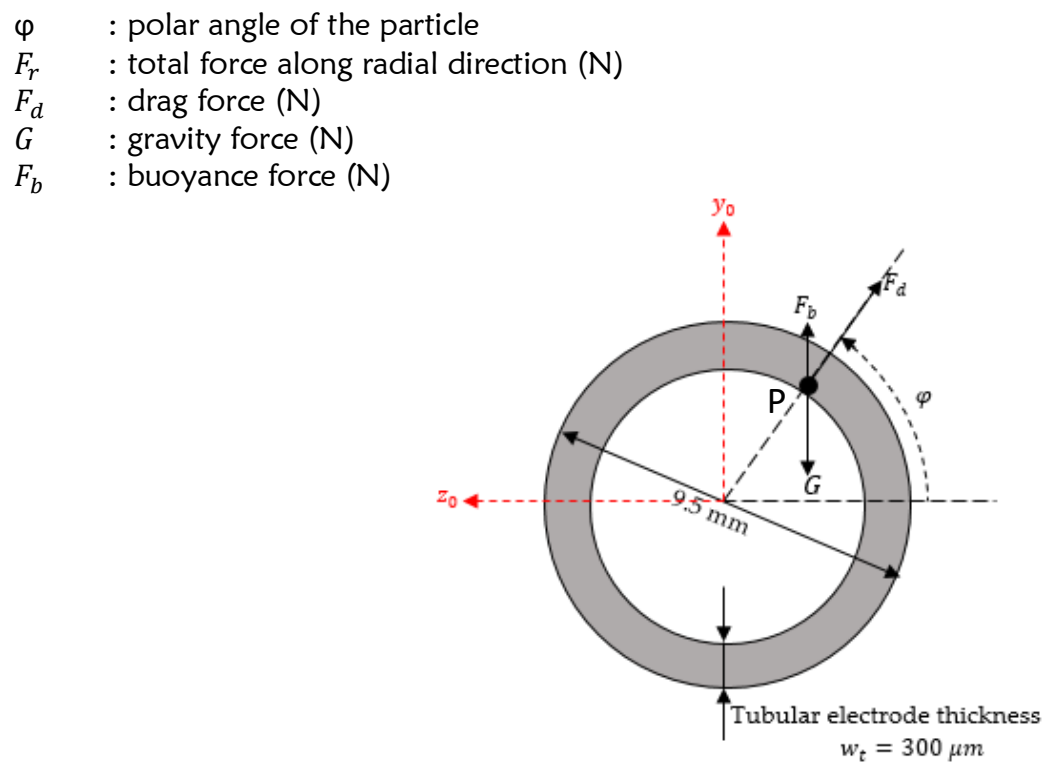

Figure 1 Free-body diagram of a particle between horizontal electrodes

Since the solid particle is heavier and sinks in electrolyte, the buoyance force of this particle is always smaller than its gravity force. The minimum value of radial direction force equals to $F_{d}-\left(G-F_{b}\right)$ when $\varphi=\pi / 2$, and the maximum value of this force equals $F_{d}+\left(G-F_{b}\right)$ when $\varphi=3 \pi / 2$. The top most location (at $\left.\varphi=\pi / 2\right)$ is the most difficult location for solid by-products to be flushed away (location A in Figure 2a). In this study, location A will be taken as the simulation cell zone. The thickness of the electrode is $0.3 \mathrm{~mm}$ (Figure 1) and the initial distance between workpiece and electrode is $0.3 \mathrm{~mm}$, thus the simulation zone is a $0.3 \mathrm{~mm} \times 0.3 \mathrm{~mm}$ square box (Figure $2 \mathrm{~b}$ ). Let the new coordinate $x y z$ with origin at the lower left corner of the simulation zone. The electrolyte flow speeds from a pump were set to 2,3 , and $4 \mathrm{~m} / \mathrm{s}$ and assuming the workpiece vibration follows a sine waveform:

$$
x=-A_{v} \sin (2 \pi f t)
$$

Let $x$ be the coordinate of the workpiece, the negative sign means the workpiece movement towards the left and away from the origin.

Where,

$x \quad$ : location of workpiece relative to the fixed origin.

$A_{v} \quad$ : anode workpiece vibration amplitude $(\mathrm{m})$

$f \quad$ : vibration frequency $(\mathrm{Hz})$. 


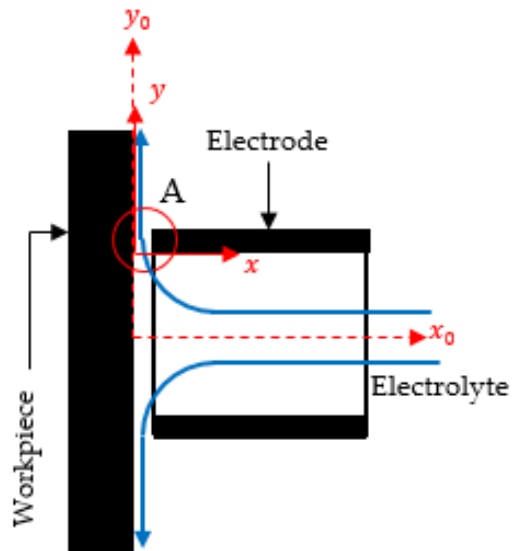

(a)

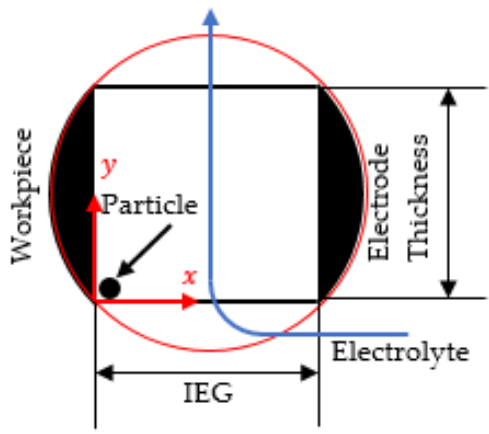

(b)

Figure 2 (a) Side view of electrode and workpiece and (b) enlarged view at the top most position

In the beginning, the particle center was located at lower left corner (Figure $2 \mathrm{~b}$ ) with particle initial velocity of $0 \mathrm{~m} / \mathrm{s}$. The boundary conditions for this study are listed in

Table 1. A simulation procedure stopped when the $y$-coordinate of particle center was larger than $0.3 \mathrm{~mm}$, i.e. when the particle was flushed away from the electrode surface.

Table 1 Boundary conditions in simulation

\begin{tabular}{ll}
\hline Variables & Values \\
\hline Vibration frequency $f(\mathrm{~Hz})$ & $20,30,40$ \\
Vibration amplitude $A(\mu \mathrm{m})$ & $5.0,7.5,10.0$ \\
Flow speed $(\mathrm{m} / \mathrm{s})$ & $2.0,3.0,4.0$ \\
\hline
\end{tabular}

Table 2 Corresponding vibration amplitude and frequency for maximum input power

\begin{tabular}{cc}
\hline $\begin{array}{c}\text { Vibration } \\
\text { Frequency } \\
(\mathrm{Hz})\end{array}$ & $\begin{array}{c}\text { Vibration } \\
\text { Amplitude } \\
(\mu \mathrm{m})\end{array}$ \\
\hline 10 & 160.00 \\
20 & 40.00 \\
30 & 17.80 \\
40 & 10.00 \\
50 & 6.40 \\
60 & 4.44 \\
70 & 3.26 \\
80 & 2.50 \\
90 & 1.98 \\
100 & 1.60 \\
110 & 1.32 \\
120 & 1.11 \\
130 & 0.95 \\
140 & 0.82 \\
150 & 0.71 \\
175 & 0.52 \\
200 & 0.40 \\
500 & 0.065 \\
1000 & 0.016 \\
5000 & 0.00064 \\
10000 & 0.00016 \\
\hline
\end{tabular}

To investigate the influence of the vibration frequency, vibration amplitude, electrolyte flow speed, particle size and particle locations on average flushing speed, a series of simulations were conducted:

1) The first simulation was used to build a relationship between experimental results and simulation results. Three input levels for each variable were set (

2) Table 1). Thus, total number of simulation run was $3^{3}=27$. 
3) The second simulation was used to theoretically investigate the maximum flushing speed for the experimental system. The electrolyte flow speed was fixed at $4 \mathrm{~m} / \mathrm{s}$, and input current for vibration table was fixed at its maximum value $(7 \mathrm{~A})$, the corresponding vibration frequency and vibration amplitude will follow $A f^{2}=$ constant based on the specifications of system and are listed in Table 2.

4) The third simulation was used to investigate the particle size on average flushing speed. The electrolyte flow speed was fixed at $4 \mathrm{~m} / \mathrm{s}$, vibration frequency was fixed at $40 \mathrm{~Hz}$, vibration amplitude was fixed at $10 \mu \mathrm{m}$ and particle sizes range from $2 \mu \mathrm{m}$ to $10 \mu \mathrm{m}$.

The discrete phase formulation used by ANSYS Fluent assumed that (i) the discrete phase (ECM by-product) was sufficiently diluted, and (ii) particle-particle interaction and the effects of the particle volume fraction on the continuous phase were negligible. This implied that the discrete phase must be present at a low volume fraction, typically less than $10-12 \%$.

\subsubsection{Multiple Particles Simulation}

The Star CCM+ was used to capture the particle-particle interaction in multiple particles fluid-particle flow system. Figure 3 shows the flow domain in yz-plane with the length of $w t=300 \mu \mathrm{m}$ and width $L a=20 \mu \mathrm{m}$. Four particle injection locations (label "I" and "II" at coordinates $z= \pm 5, y=50 \mu \mathrm{m}$; and label "III" and "IV" at coordinates $z=$ $\pm 5, y=0 \mu \mathrm{m}$ ) were continuously injecting particles of $2 \mu \mathrm{m}$ diameter into the electrolyte between the electrode and workpiece.

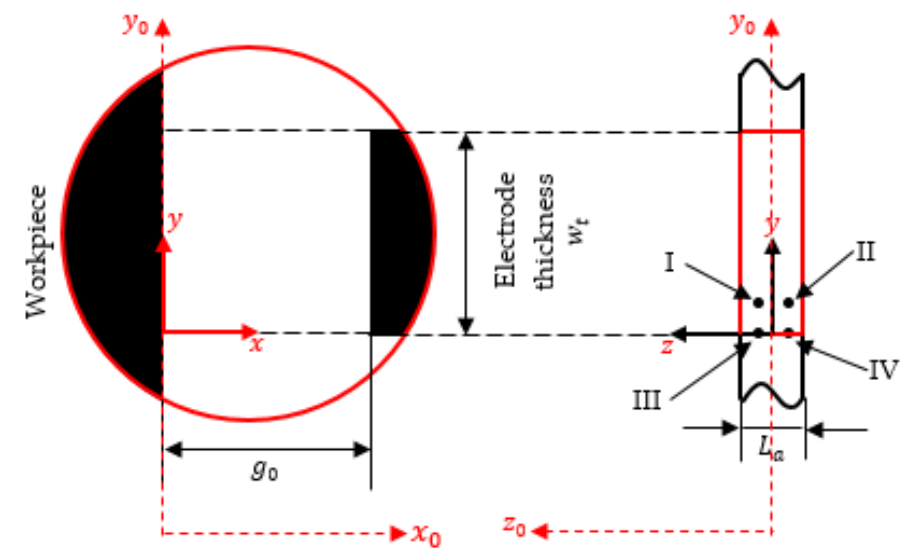

Figure 3 Particle injection locations in fluid domain

Due to the limitation of the simulation software, a triangular wave was used as the approximation of the sine wave (Figure 4). During a vibration cycle the workpiece moved at a constant speed of $4 f A_{v}$ before changing its direction. The by-product particles in ECM were released from the workpiece surface, and their releasing locations changed continuously. To simplify the simulation, a vibration cycle was divided into 20 equal time intervals within which the releasing locations were fixed. When the workpiece moved away from the electrode, particle releasing locations were the same as their initial locations from each time interval; in the reversed direction of workpiece, the particle releasing locations were the ending locations of each time interval.

In this simulation, the vibration was fixed at $40 \mathrm{~Hz}$ at $10 \mu \mathrm{m}$. The workpiece travel speed was $4 f A_{v}=1600 \mu \mathrm{m} / \mathrm{s}$, and the article releasing rate was $10^{5}$ particles/s. The complete list of particles releasing locations for one vibration cycle is listed in Table 3.

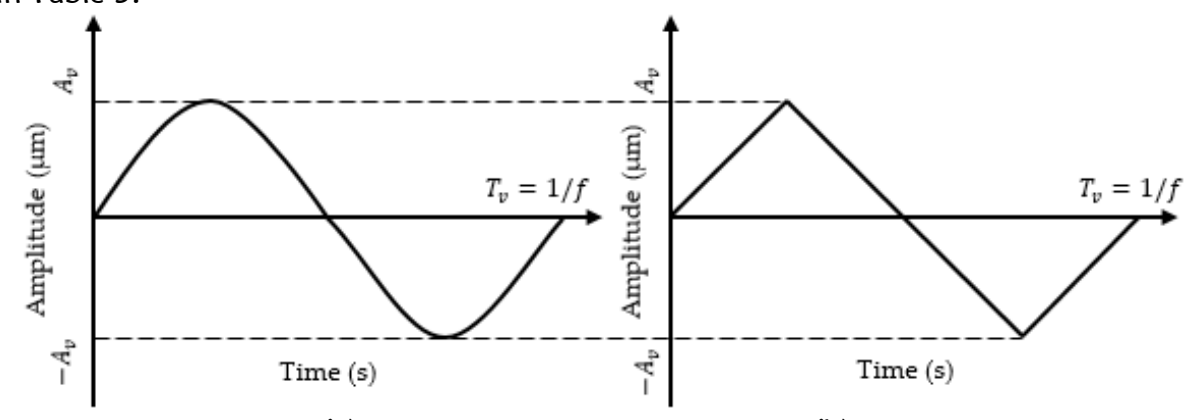

(a)

(b)

Figure 4 (a) Sine wave (b) Approximation of sine wave in Star CCM+ 
Table 3 Coordinates of particle injection locations

\begin{tabular}{ccccc}
\hline $\begin{array}{c}\text { Simulation Time } \\
(\mathrm{ms})\end{array}$ & $\begin{array}{c}\text { Location I }(\mu \mathrm{m}) \\
\left(x_{1 j}, y_{1 j}, z_{1 j}\right)\end{array}$ & $\begin{array}{c}\text { Location II }(\mu \mathrm{m}) \\
\left(x_{2 j}, y_{2 j}, z_{2 j}\right)\end{array}$ & $\begin{array}{c}\text { Location III }(\mu \mathrm{m}) \\
\left(x_{3 j}, y_{3 j}, z_{3 j}\right)\end{array}$ & $\begin{array}{c}\text { Location IV }(\mu \mathrm{m}) \\
\left(x_{4 j}, y_{4 j}, z_{4 j}\right)\end{array}$ \\
\hline $0-1.25$ & $(1,50,5)$ & $(1,50,-5)$ & $(1,0,5)$ & $(1,0,-5)$ \\
$1.25-2.50$ & $(-1,50,5)$ & $(-1,50,-5)$ & $(-1,0,5)$ & $(-1,0,-5)$ \\
$2.50-3.75$ & $(-3,50,5)$ & $(-3,50,-5)$ & $(-3,0,5)$ & $(-3,0,-5)$ \\
$3.75-5.00$ & $(-5,50,5)$ & $(-5,50,-5)$ & $(-5,0,5)$ & $(-5,0,-5)$ \\
$5.00-6.25$ & $(-7,50,5)$ & $(-7,50,-5)$ & $(-7,0,5)$ & $(-7,0,-5)$ \\
$6.25-7.50$ & $(-7,50,5)$ & $(-7,50,-5)$ & $(-7,0,5)$ & $(-7,0,-5)$ \\
$7.50-8.75$ & $(-5,50,5)$ & $(-5,50,-5)$ & $(-5,0,5)$ & $(-5,0,-5)$ \\
$8.75-10.00$ & $(-3,50,5)$ & $(-3,50,-5)$ & $(-3,0,5)$ & $(-3,0,-5)$ \\
$10.00-11.25$ & $(-1,50,5)$ & $(-1,50,-5)$ & $(-1,0,5)$ & $(-1,0,-5)$ \\
$11.25-12.50$ & $(1,50,5)$ & $(1,50,-5)$ & $(1,0,5)$ & $(1,0,-5)$ \\
$12.50-13.75$ & $(3,50,5)$ & $(3,50,-5)$ & $(3,0,5)$ & $(3,0,-5)$ \\
$13.75-15.00$ & $(5,50,5)$ & $(5,50,-5)$ & $(5,0,5)$ & $(5,0,-5)$ \\
$15.00-16.25$ & $(7,50,5)$ & $(7,50,-5)$ & $(7,0,5)$ & $(7,0,-5)$ \\
$16.25-17.50$ & $(9,50,5)$ & $(9,50,-5)$ & $(9,0,5)$ & $(9,0,-5)$ \\
$17.50-18.75$ & $(11,50,5)$ & $(11,50,-5)$ & $(11,0,5)$ & $(11,0,-5)$ \\
$18.75-20.00$ & $(11,50,5)$ & $(11,50,-5)$ & $(11,0,5)$ & $(11,0,-5)$ \\
$20.00-21.25$ & $(9,50,5)$ & $(9,50,-5)$ & $(9,0,5)$ & $(9,0,-5)$ \\
$21.25-22.50$ & $(7,50,5)$ & $(7,50,-5)$ & $(7,0,5)$ & $(7,0,-5)$ \\
$22.50-23.75$ & $(5,50,5)$ & $(5,50,-5)$ & $(5,0,5)$ & $(5,0,-5)$ \\
$23.75-25.00$ & $(3,50,5)$ & $(3,50,-5)$ & $(3,0,5)$ & $(3,0,-5)$ \\
\hline
\end{tabular}

\section{EXPERIMENTS}

To carry out this investigation, a unique laboratory horizontal vibration-assisted pulsed ECM system was developed (Figure 5). This ECM system can control electrolyte flow, vibration frequency and amplitude, square pulsed DC output and programmable tool feeding. The system (Table 4) included micro workpiece vibration unit, controllable pulsed DC system, programmable feeding system, electrolyte circulation system, and ECM cell with flash guard, etc.
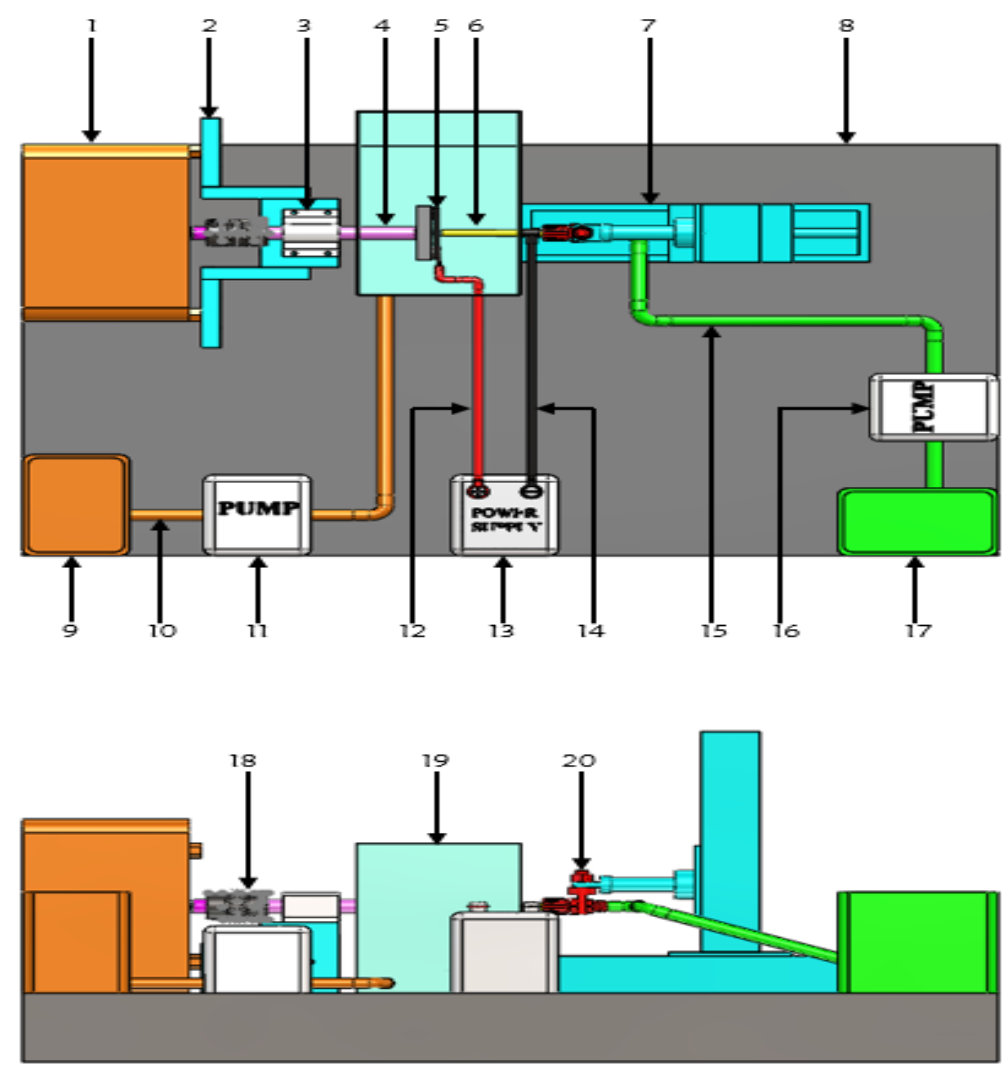

Figure 5 Front and top views of the laboratory horizontal ECM system 
Table 4 ECM set-up components

\begin{tabular}{llll}
\hline$\#$ & Components Name & $\#$ & Component Name \\
\hline 1 & Labworks electrodynamic shaker & 11 & Longer WT600-2J peristaltic pump \\
2 & Bearing housing & 12 & Positive electric wire \\
3 & Linear bearing & 13 & Everlast 255EXT power supply \\
4 & Stainless steel shaft & 14 & Negative electric wire \\
5 & Workpiece & 15 & Fresh-electrolyte tube \\
6 & Electrode & 16 & Longer WT600-2J peristaltic pump \\
7 & 3-axis Velmex positioner & 17 & Fresh-electrolyte container \\
8 & Granite table & 18 & Shaft coupling \\
9 & Used-electrolyte container & 19 & ECM cell with flash guard housing \\
10 & Used-electrolyte tube & 20 & Electrode holder \\
\hline
\end{tabular}

A workpiece plate (\#5) was mounted with workpiece surface in vertical direction and an electrode (\#6) traveled horizontally into the workpiece with feed rate controlled by a computer-controlled positioner (\#7). Workpiece vibration was precisely generated by an electrodynamic shaker (\#1). A pulsed power supply (\#13) and two high-flowrate pumps $(\# 11,16)$ completed the ECM cell.

In this study, the constant concentration of potassium bromide $(\mathrm{KBr}, 1 \mathrm{~mol} / \mathrm{L})$ was selected as electrolyte. Each experimental run was started with filtered electrolyte temperature in the range $21-29^{\circ} \mathrm{C}$. Temperature of the electrolyte was measured and recorded by OMEGA HH374 4-channel data logger thermometer. Electrolyte conductivity, measured before each run using the Hannah HI 8733 conductivity meter, was in the range of 111-121 $\mathrm{mS} / \mathrm{cm}$. During experimental, fresh electrolyte was pumped from fresh electrolyte container (\#16) and flowed inside the cathodic electrode (\#4). After machining, used electrolyte in the ECM cell (\#5) was pumped out and stored in used electrolyte container (\#8). Although the metallic by-products in used electrolyte could be filtered using centrifugal method in small quality, the settling method was used for a large quantity of used electrolyte. In the latter method the used electrolyte, mixed with metal debris and by-products, was stored overnight so that the heavy metallic and salt-byproduct would be settled at the contained bottom. The clear electrolyte at the top was pump back to the fresh electrolyte container (\#16) using a Longer WT600-2J peristaltic pump (\#15) and reused for subsequent experiment if its conductivity was still comparable with that of the fresh electrolyte.

The EVERLAST 255 EXT DC power supply provides either DC or pulsed DC of 3-150 A up to $500 \mathrm{~Hz}$ pulsed current frequency. Since a high peak current may generate sparks that damage the workpiece and electrode, the constant peak current was set at $26 \mathrm{~A}$, current frequency at $500 \mathrm{~Hz}$ and $50 \%$ duty cycle.

Stainless steel tubes ( $\phi 9.5 \mathrm{~mm}$ OD, $0.3 \mathrm{~mm}$ thick, \#4) were selected as cathodic electrode. About $13 \mathrm{~mm}$ ends were commercially coated with Teflon to form a nonconductive layer of $0.02 \mathrm{~mm}$ thick on both outside and inside diameters. The coated ends were carefully sanded off using 600-grit abrasive paper to make the cathodic electrode tube conductive.

The Labworks ET-132-2 electrodynamic shaker was powered by the Labworks PA-151 linear power amplifier that in turn controlled by an Agilent 33250A waveform generator. The computer-controlled positioner included two Velmex motorized frames, a rotary plate and a VXM-3 controller system. The system has a load capacity of $15.9 \mathrm{~kg}$ horizontally and $4.5 \mathrm{~kg}$ vertically with straight-line accuracy of $0.076 \mathrm{~mm} / 25 \mathrm{~cm}$, feed rate range $2.5-5000 \mu \mathrm{m} / \mathrm{s}$, and repeatability of $0.0025 \mathrm{~mm}$.

The TENMA 72-6202 multimeter was used to measure the conductivity between the cathodic electrode and the anodic workpiece. The Velmex computer-controlled positioner was used to set the initial inter-electrode gap. At first, the multimeter was used to find the location of the cathodic electrode where in contact with the anodic workpiece since the resistance between the cathodic electrode and the anodic workpiece dropped to $0(\mathrm{IEC}=0)$. After that, the cathodic electrode moved back $0.3 \mathrm{~mm}$ and controlled by the Velmex positioner. In this investigation, a constant feed rate was set to $15 \mu \mathrm{m} / \mathrm{s}$ and the cathodic electrode traveled a distance of $2.5 \mathrm{~mm}$. All experimental conditions are summarized in Table 5.

After ECM'ed, all samples were rinsed and cleaned with water in an ultrasonic bath for one minute and then dried with compressed air. All samples were positioned in a grass beaker in the bath with ECM'ed holes facing down to facilitate removal of residual particles from the hole. The Alicona Infinite Focus 3D profiler was used to analyze the ECM'ed machined depth, surface finish and wall taper angle.

The settled by-products were collected and washed with distilled water 10 times to remove the dissolved potassium bromide. Two samples of by-products were prepared for SEM and EDX. The sample for SEM was one drop of by-products solution placed on the titanium plate and dried in air. Thin Au-Pd layer was sputtered coated on the surface of the titanium and specimens. The Tescan Vega 3 SEM was used to capture the surface image of the by-products. The ECM sediment was washed, dried, and deposited on a carbon tape. The Zeiss EDX was used to analysis the by-products compositions. 
Table 5 Summary of experimental conditions

\begin{tabular}{ll}
\hline Variables & Values \\
\hline Current frequency $(\mathrm{Hz})$ & 500 \\
Electrode feed rate $(\mu \mathrm{m} / \mathrm{s})$ & 15 \\
Electrode travel distance $(\mathrm{mm})$ & 2.5 \\
Electrolyte concentration $(\mathrm{mol} / \mathrm{L})$ & 1 \\
Electrolyte conductivity $(\mathrm{mS} / \mathrm{cm})$ & $111-121$ \\
Electrolyte flow rate $(\mathrm{L} / \mathrm{min})$ & 2.5 \\
Starting IEC $(\mathrm{mm})$ & 0.3 \\
Peak current $(\mathrm{A})$ & 26 \\
Vibration amplitude $(\mu \mathrm{m})$ & $0,2.50,4.44,5.00,7.50,10.00$ \\
Vibration frequency $(\mathrm{Hz})$ & $0,20,30,40,60,80$ \\
\hline
\end{tabular}

\section{RESULTS AND DISCUSSIONS}

Simulation results from ANSYS Fluent for flushing speed, the effect of vibration frequency, and electrolyte flow rate are presented first. The particle interaction results from STAR CCM+ simulation are then followed. Experimental trends are finally presented and compared with the simulation data.

\subsection{Average Flushing Speeds}

Recall that the simulation cell is $0.3 \mathrm{~mm} \times 0.3 \mathrm{~mm}$ (Figure 6a), and a simulation will be terminated if the $y$-coordinate of a particle center is larger than $0.3 \mathrm{~mm}$, i.e, a particle is effectively flushed and traveled outside of the interelectrode gap. Typical particle trajectory along $y$-direction as a function of time is shown in Figure 6 . The average flushing speed, $V_{\text {ave }}$, is defined as the secant slope of particle path:

$$
V_{\text {ave }}=\frac{\text { particle travel distance }}{\text { travel time }}=\frac{300 \mu \mathrm{m}}{756 \mu \mathrm{s}}=0.396 \mathrm{~m} / \mathrm{s}
$$

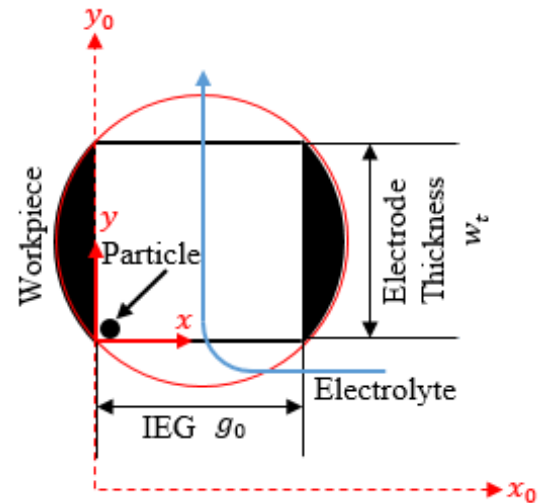

(a)

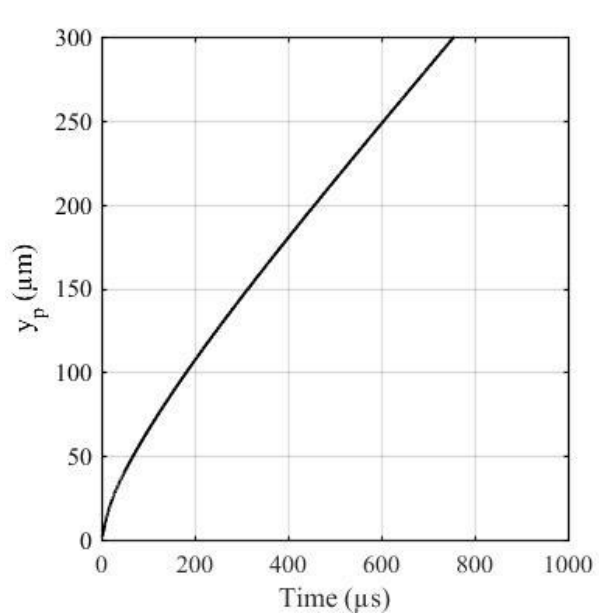

(b)

Figure 6 Particle movement in y-direction. Vibration $40 \mathrm{~Hz}$ at $10 \mu \mathrm{m}$, electrolyte flow rate $4 \mathrm{~m} / \mathrm{s}$. (Simulation with ANSYS Fluent at $f=40 \mathrm{~Hz}, A_{v}=10 \mu \mathrm{m}$, and $V_{e}=4 \mathrm{~m} / \mathrm{s}$ )

The effect of vibration frequency on average flushing speed when the driving current for vibration table was set at $I_{\text {vibration }}=7 \mathrm{~A}$ is shown in Figure 7 . The average flushing speed decreases with increasing vibration frequency. Neglecting the effect of the workpiece vibration on the particle movement along the cathodic electrode $x$-direction, the distance between workpiece and the particle center is given in Equation (17) and illustrated in Figure 8.

$$
d_{g}=-A_{v} \sin (2 \pi f t)+r_{p}
$$

Where,

$d_{g}$ : Gap between particle and workpiece surface $\left(\geq r_{p}\right)(\mu \mathrm{m})$

$A_{v}:$ Vibration amplitude $(\mu \mathrm{m})$

$f \quad$ : Vibration frequency $(\mathrm{Hz})$

$r_{p} \quad$ : Particle diameter $(\mu \mathrm{m})$ 


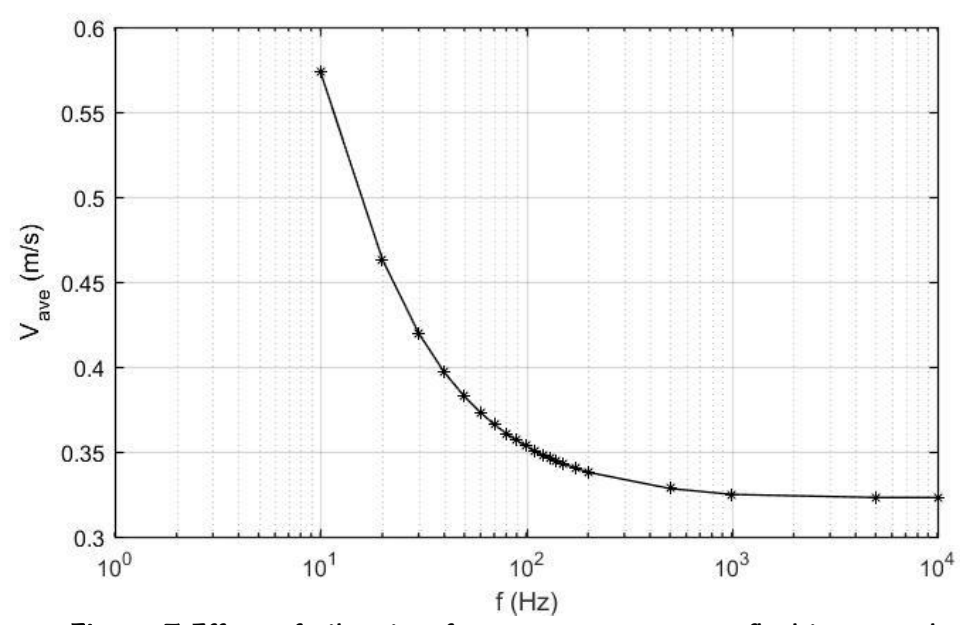

Figure 7 Effect of vibration frequency on average flushing speed.

(Simulation with ANALYS Fluent at $I_{\text {vibration }}=7 \mathrm{~A}$ )

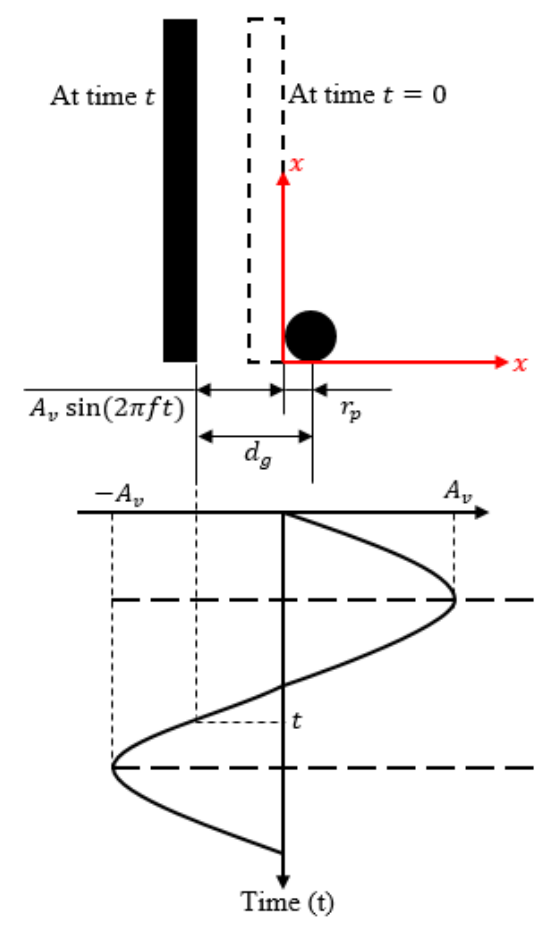

Figure 8 Illustration of the distance between particle center and workpiece surface.

As shown in Figure 7, $I_{\text {vibration }}$ is fixed at $7 \mathrm{~A}$, the average flushing speed decreases from $0.5736 \mathrm{~m} / \mathrm{s}($ at $f=10 \mathrm{~Hz}$, $A_{v}=160 \mu \mathrm{m}$ ) to $0.3231 \mathrm{~m} / \mathrm{s}$ (at $f=10,000 \mathrm{~Hz}, A_{v}=0.16 \mu \mathrm{m}$ ) when vibration frequency increases from $10 \mathrm{~Hz}$ to $10,000 \mathrm{~Hz}$. For fixed vibration current or constant vibration power, the vibration amplitude and vibration frequency follow the relationship $A_{v} f^{2}=$ constant $B$, and Equation (17) becomes:

$$
d_{g}=-B \frac{\sin (2 \pi f t)}{f^{2}}+r_{p}
$$

Equation (18) suggests that the distance between particle center and workpiece $d_{g}$ decreases drastically with increasing vibration frequency $f$. Therefore, for fixed current on vibration generator, a high vibration frequency would lead to a smaller gap, lower drag force and lower average flushing speed, as shown in Figure 7.

The relationship between particle size and average flushing speed is shown in Figure 9. As the particle radius increases from $1 \mu \mathrm{m}$ to $3 \mu \mathrm{m}$, the average flushing speed increases from 0.29 to $2.77 \mathrm{~m} / \mathrm{s}$. However, continue increase particle size to $5 \mu \mathrm{m}$, the average flushing speed changes slightly, from 2.77 to $3.08 \mathrm{~m} / \mathrm{s}$. This is because the gap $d_{g}$ 
in Equation (18) increases with an increasing of particle radius. Larger gap results in higher drag force and higher average flushing speed.

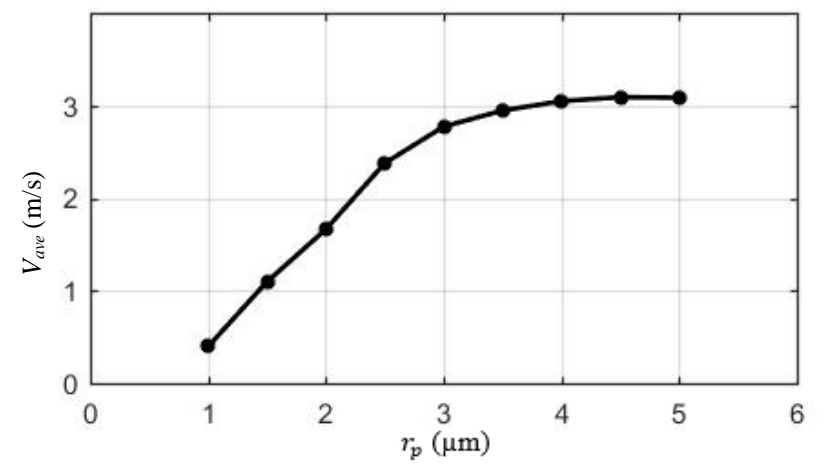

Figure 9 Relationship between average flushing speed and particle radius.

(Simulation with ANASYS Fluent at $f=40 \mathrm{~Hz}$ and $A_{v}=10 \mu \mathrm{m}$ and $V_{e}=4 \mathrm{~m} / \mathrm{s}$ )

This simulation results were confirmed with experiment results conducted in another study [12]. For a preset machining parameter combinations $(4 \mu \mathrm{m}, 6 \mu \mathrm{m}$ and $8 \mu \mathrm{m}$ vibration amplitude, $\phi 160 \mu \mathrm{m}$ tungsten cathodic electrode with $5 \mu \mathrm{m}$ insulate layer, 321 stainless steel workpiece with $0.5 \mathrm{~mm}$ thickness, $5 \mathrm{wt} \% \mathrm{NaNO}_{3}+0.8 \mathrm{wt} \% \mathrm{EDTA}_{\mathrm{N}} \mathrm{Na}_{2}$ electrolyte, $6 \mathrm{~V}$ voltage with $50 \%$ duty cycle, $2 \mathrm{kHz}$ pulsed voltage and $15.6 \mu \mathrm{m} \mathrm{IEG),} \mathrm{after} \mathrm{obtaining} \mathrm{the} \mathrm{maximum}$ MRR at a $50 \mathrm{~Hz}$, the MRR decreased with increasing of vibration frequency, as shown in Figure 10.

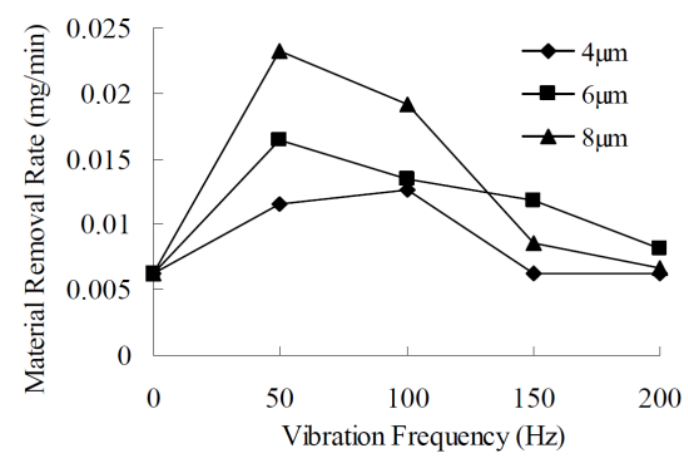

Figure 10 Effect of vibration frequency on the MRR, reprinted from [12].

\subsection{Effect of Vibration on Average Flushing Speed and Part Quality}

The effects of vibration frequency and amplitude on average flushing speed, depth of material removal, and taper angle are presented in this section. Figure 11a,b show how the flushing speed and machined depth when varying the vibration parameters. At every vibration amplitude, the average flushing speed increases as the vibration frequency increases. The maximum average flushing speed, $0.396 \mathrm{~m} / \mathrm{s}$, is obtained at $40 \mathrm{~Hz}$ vibration frequency and $10 \mu \mathrm{m}$ vibration amplitude. For a specific vibration amplitude $A_{v}$, when the vibration frequency increasing, the gap between the anodic electrode surface and the particle center is increased, hence the drag force exert on the particle is increased which result in an increasing average particle flushing speed.

At every vibration amplitude $(5,7.5$, and $10 \mu \mathrm{m})$, a higher vibration frequency leads to faster average flushing speed and deeper machining depth.

- When vibration frequency increases from 20 to $40 \mathrm{~Hz}$, the average flushing speeds increase by $5.4 \%$ (from 0.3423 to $0.3608 \mathrm{~m} / \mathrm{s}$ ), $7.8 \%$ (from 0.3517 to $0.3790 \mathrm{~m} / \mathrm{s}$ ) and $9.9 \%$ (from 0.3610 to $0.3968 \mathrm{~m} / \mathrm{s}$ ), at respective vibration amplitude.

- Improving of flushing speed changes machining depths by $2.9 \%$ (from 1282 to $1319 \mu \mathrm{m}$ ), $9.9 \%$ (from 1308 to $1437 \mu \mathrm{m}$ ) and $18.6 \%$ (from 1336 to $1584 \mu \mathrm{m}$ ), respectively. 


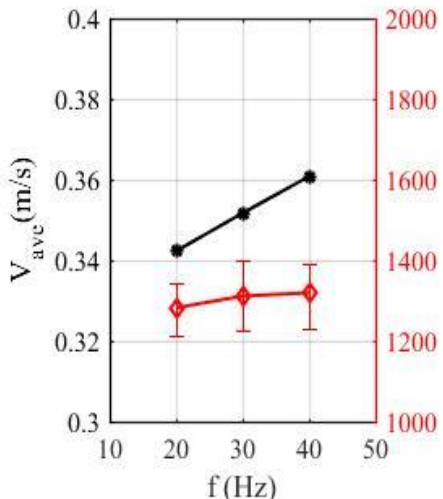

(a) $A_{v}=5.0 \mu \mathrm{m}$

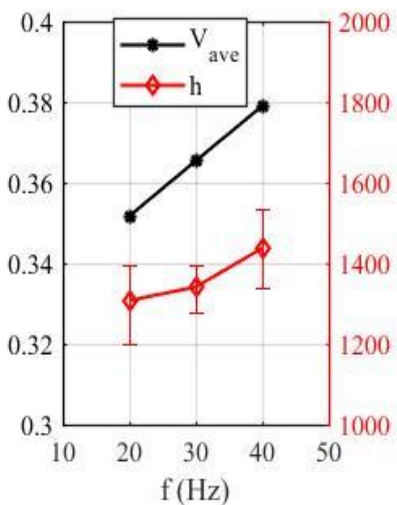

(b) $A_{v}=7.5 \mu \mathrm{m}$

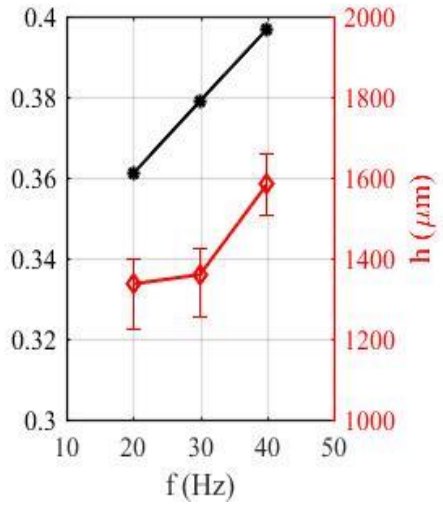

$\mathrm{A}_{v}=10.0 \mu \mathrm{m}$

Figure 11a Effect of vibration amplitude on average flushing speed (left vertical scale) and machining depth (right vertical scale)

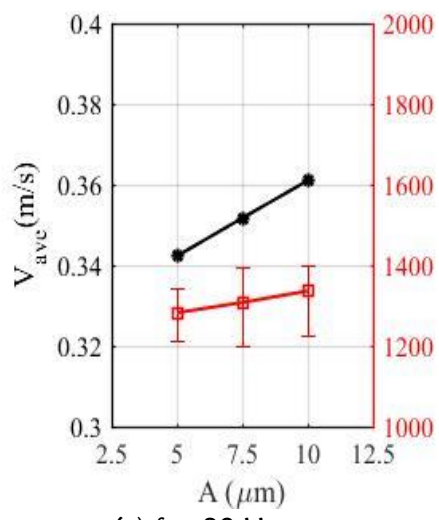

(a) $\mathrm{f}=20 \mathrm{~Hz}$

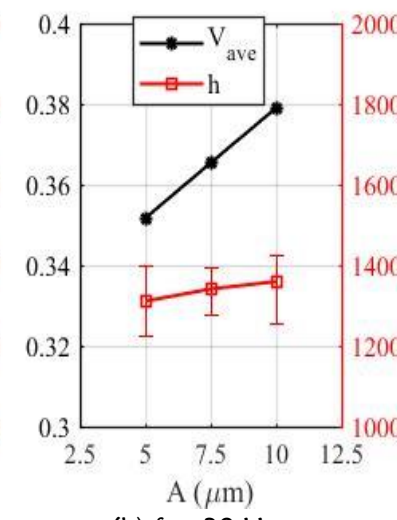

(b) $\mathrm{f}=30 \mathrm{~Hz}$

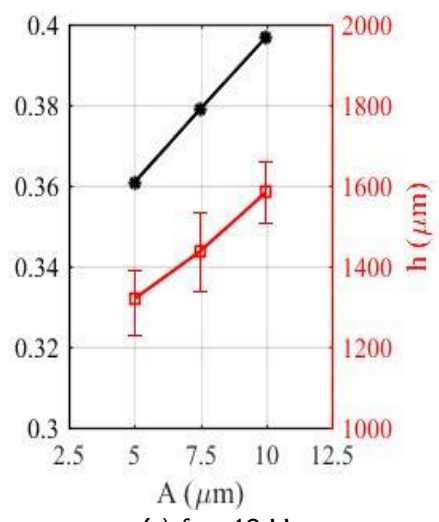

(c) $\mathrm{f}=40 \mathrm{~Hz}$

Figure 11b Effect of vibration frequency on average flushing speed (left vertical scale) and machining depth (right vertical scale)

Vibration-assisted ECM increases the machined depth of a hole while reducing the hole taper angle, therefore, enhancing the product quality. The effects of vibration frequency on average flushing speed and taper angle are illustrated in Figure 12a,b.

- At every vibration frequency $(20,30$, and $40 \mathrm{~Hz})$, a higher vibration amplitude leads to faster flushing speed and smaller taper angle - therefore, straighter and sharper hole profile. When vibration amplitude increases from 5.0 to $10.0 \mu \mathrm{m}$, the taper angles decreases by $8.7 \%$ (from 31.92 to $29.15^{\circ}$ ), $12.8 \%$ (from 29.32 to $25.56^{\circ}$ ) and $43.4 \%$ (from 29.28 to $16.57^{\circ}$ ), at respective vibration frequency.

- At every vibration amplitude $(5,7.5$, and $10 \mu \mathrm{m})$, a higher vibration frequency leads to a smaller taper angle. When vibration frequency increases from 20 to $40 \mathrm{~Hz}$, the taper angles decrease by $3.4 \%$ (from 31.92 to $29.28^{\circ}$ ), $27.3 \%$ (from 29.81 to $21.67^{\circ}$ ) and $43.2 \%$ (from 29.15 to $16.57^{\circ}$ ) at corresponding vibration amplitude.

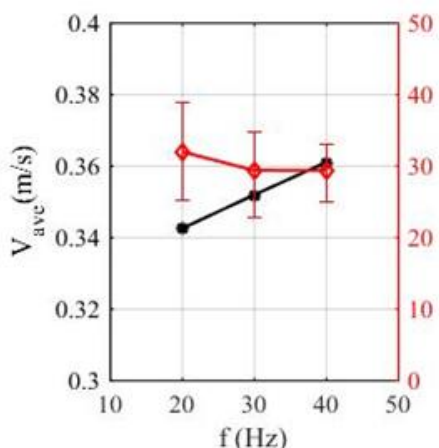

(a) $A_{v}=5.0 \mu \mathrm{m}$

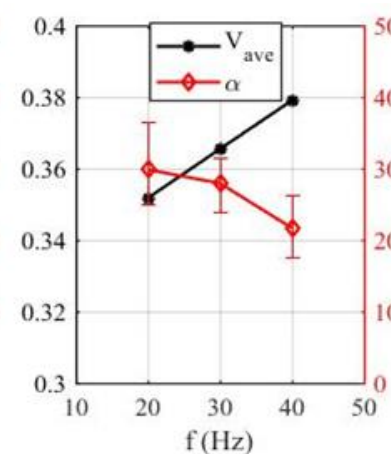

(b) $A_{v}=7.5 \mu \mathrm{m}$

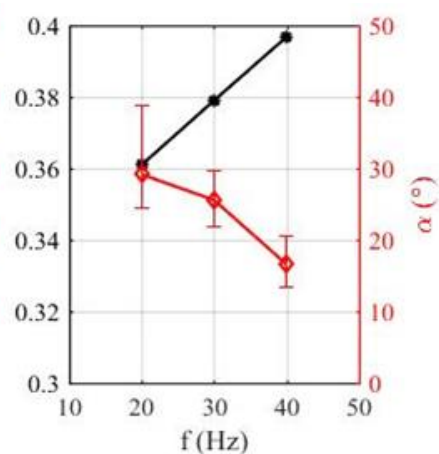

$\mathrm{A}_{\mathrm{v}}=10.0 \mu \mathrm{m}$

Figure 12a Effect of vibration amplitude on average flushing speed (left vertical scale) and taper angle (right vertical scale) 


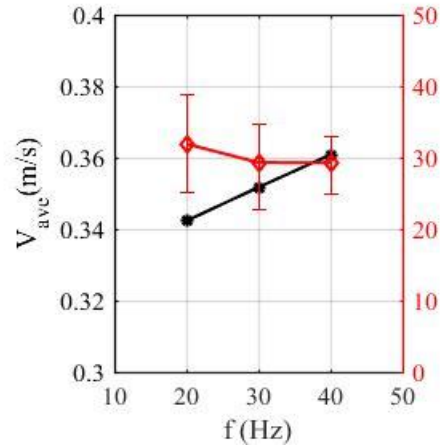

(a) $\mathrm{f}=20 \mathrm{~Hz}$

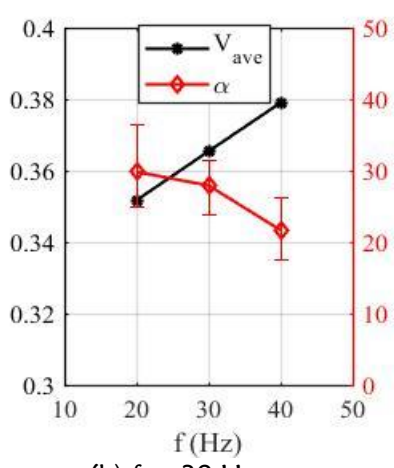

(b) $\mathrm{f}=30 \mathrm{~Hz}$

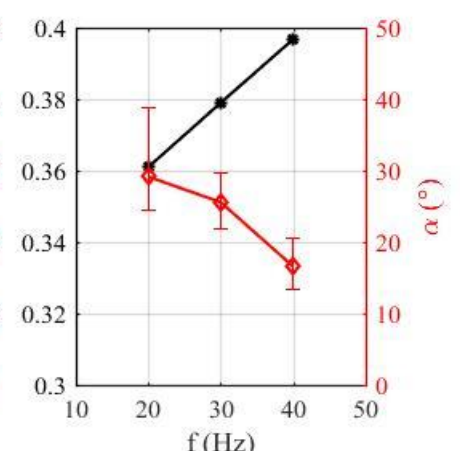

(c) $\mathrm{f}=40 \mathrm{~Hz}$

Figure 12b Effect of vibration frequency on average flushing speed (left vertical scale) and taper angle (right vertical scale)

The simulation results and experimental data trends presented above agree with other studies. Simulation and experimental data suggest a negative correlation between average flushing speed and taper angle. The similar trend was also reported on hole shape after ECM (using brass tube cathodic electrode with $\phi 8 \mathrm{~mm}$ outer diameter and $\phi 3.5 \mathrm{~mm}$ inner diameter, $20 \mathrm{~g} / \mathrm{L} \mathrm{NaCl}$ electrolyte, $6 \mathrm{~L} / \mathrm{min}$ electrolyte flow rate, $1 \mathrm{~mm} / \mathrm{min}$ cathodic electrode feed rate, $18 \mathrm{~V}$ applied voltage and $50 \mathrm{~Hz}$ vibration frequency [11]); the conicity (slope of a cone) decreased from 3.95 to $3.25 \%$ when vibration amplitude increased from 20 to $100 \mu \mathrm{m}$. This trend can also be explained qualitatively:

i. Vibration of workpiece leads to a higher flushing speed that breaks up agglomerated groups of by-products into smaller chunks of particles.

ii. The smaller chunks forming between two electrodes then travel up the wall of hole and outside of the interelectrode zone. The smaller coalesced particles would erode the wall less and result in smaller taper angle and sharper hole profile.

Low frequency vibration of workpiece increases the flushing speed, enhances ion transport rate and leads to more effective machining rate. Similar results were also reported in other experimental studies in which an ECM system utilized $\phi 160 \mu \mathrm{m}$ tungsten cathodic electrode with $5 \mu \mathrm{m}$ insulate layer, 321 stainless steel anodic workpiece with 0.5 mm thickness, 5 wt $\% \mathrm{NaNO}_{3}+0.8 \mathrm{wt} \%$ EDTA-Na $\mathrm{Na}_{2}$ electrolyte, $6 \mathrm{~V}$ voltage with $50 \%$ duty cycle, $2 \mathrm{KHz}$ pulsed voltage and $15.6 \mu \mathrm{m} \mathrm{IEG,} \mathrm{3-14} \mu \mathrm{m}$ vibration amplitude, and 50-200 Hz vibration frequency [12]. That study reported that:

i. At any vibration amplitude $(4,6$, and $8 \mu \mathrm{m})$, the MRR increased when increasing vibration frequency from $0 \mathrm{~Hz}$ to $50 \mathrm{~Hz}$. However, the MRR dropped when increasing frequency further to $200 \mathrm{~Hz}$.

ii. At both vibration frequencies $(50 \mathrm{~Hz}$ and $100 \mathrm{~Hz})$, the MRR increased with increasing vibration amplitude in the range $0-8 \mu \mathrm{m}$. The maximum MRR was obtained when vibrating at $8 \mu \mathrm{m}$ amplitude for any vibration frequency.

\subsection{Effect of Electrolyte Flow Rate on Average Flushing Speed}

The effect of electrolyte flow rates on particle average flushing speeds is illustrated with simulation data (Figure 13a,b).

- At $20 \mathrm{~Hz}$ and $5 \mu \mathrm{m}$ vibration, when the electrolyte flow rate increases from 2 to $4 \mathrm{~m} / \mathrm{s}$, the average flushing speed increases from 0.152 to $0.342 \mathrm{~m} / \mathrm{s}$.

- At $40 \mathrm{~Hz}$ and $10 \mu \mathrm{m}$ vibration, the average flushing speed increases from 0.198 to $0.396 \mathrm{~m} / \mathrm{s}$.

- For each combination of vibration frequency and vibration amplitude, the average flushing speed seems to be proportional to the electrolyte flow rate.

For a single sphere particle in a fluid, Newton's equation is used to determine the drag resistance force. The particlefluid drag coefficient, $C_{d}$, is dependent upon Reynold's number, $R_{e}$, in addition to liquid properties. There are three regions: the Stoke's Law region, the transition region and Newton's law region. By adopting the coefficients from another study [43], the fluid-particle interaction drag force can be modeled as:

$$
\begin{gathered}
\overrightarrow{F_{f}}=\overrightarrow{F_{d}}+\overrightarrow{F_{b}}=m \frac{\overrightarrow{V_{F}}-\overrightarrow{V_{p}}}{\tau_{r}}-V_{i} \rho_{F} \vec{g} \\
\tau_{r}=\frac{\rho_{p} d_{p}^{2}}{18 \mu} \frac{24}{C_{d} R_{e}}
\end{gathered}
$$




$$
\begin{aligned}
R_{e} & \equiv \frac{\rho_{F} d_{p}\left|\vec{V}_{p}-\overrightarrow{V_{F}}\right|}{\mu} \\
C_{d} & =a_{1}+\frac{a_{2}}{R_{e}}+\frac{a_{3}}{R_{e}}
\end{aligned}
$$

Where,

$F_{f}$ : Particle-fluid interaction force on particle $(\mathrm{N})$

$F_{d}$ : Drag force (N)

$F_{b}$ : Buoyance force $(\mathrm{N})$

$m$ : Particle mass $(g)$

$V_{F} \quad$ : Fluid phase flow velocity $(\mathrm{m} / \mathrm{s})$

$V_{p}$ : Particle flow velocity $(\mathrm{m} / \mathrm{s})$

$V_{i} \quad$ : Translation velocity of particle $i$ respectively $(\mathrm{m} / \mathrm{s})$

$\rho_{F} \quad$ : Fluid density $\left(\mathrm{g} / \mathrm{mm}^{3}\right)$

$\rho_{P} \quad$ : Particle density $\left(\mathrm{g} / \mathrm{mm}^{3}\right)$

$\tau_{r}$ : Particle relaxation time

$d_{p}$ : Particle diameter $(\mathrm{m})$

$\mu \quad$ : Viscosity of the fluid (Pa.s)

$C_{d}$ : Drag coefficient

$R_{e} \quad$ : Reynold's number

For an increasing fluid velocity $V_{F}$, the particle-fluid interaction force on particle $F_{f}$ is increased, which leads to an increasing particle average flushing speed $V_{\text {ave }}$.

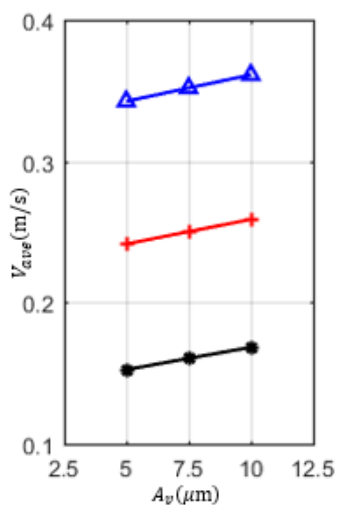

(a) $f=20 \mathrm{~Hz}$

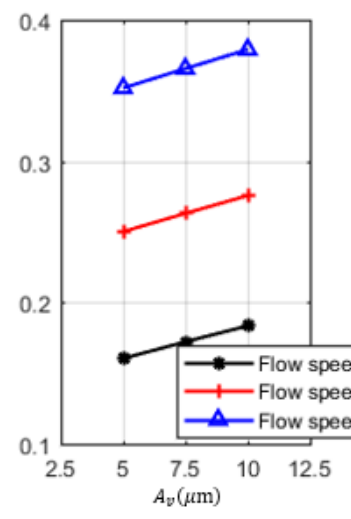

(b) $f=30 \mathrm{~Hz}$

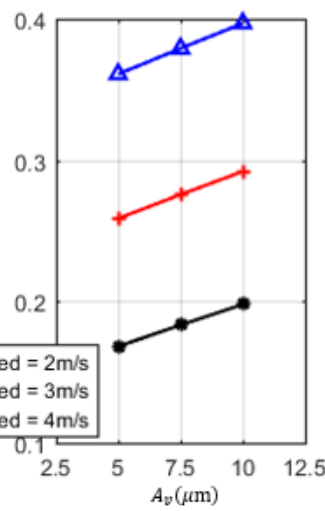

(c) $f=40 \mathrm{~Hz}$

Figure 13a Effect of electrolyte flow speed on particle average flushing speed at every vibration frequency.

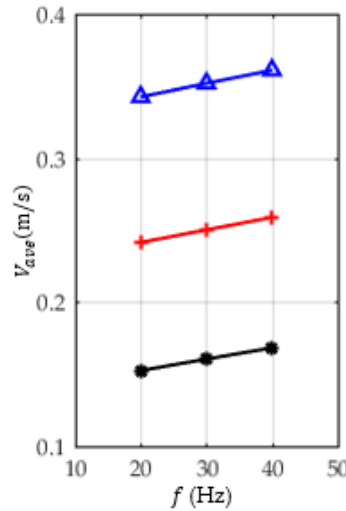

(a) $A_{v}=5.0 \mu \mathrm{m}$

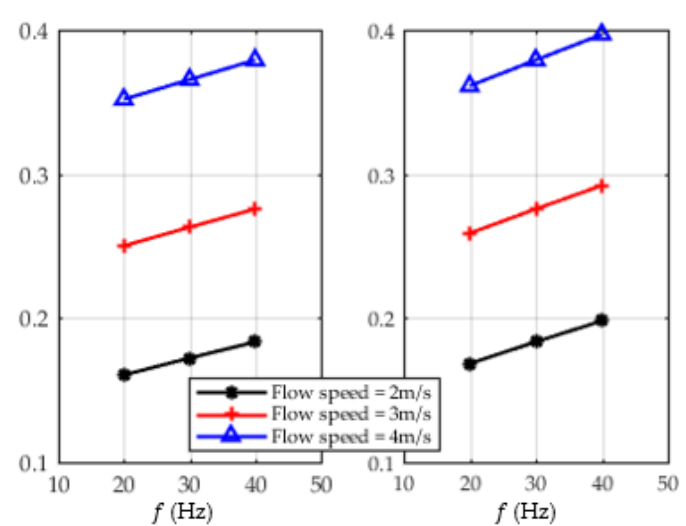

(b) $A_{v}=7.5 \mu \mathrm{m}$

(c) $A_{v}=10.0 \mu \mathrm{m}$

Figure 13b Effect of electrolyte flow speed on particle average flushing speed at every vibration amplitude. 


\subsection{Multiple Particle Interactions}

This section presents the simulation results of possible interaction among ECM particles within an interelectrode gap. Figure 14 illustrates the initial conditions of the simulation. The blue color bar on the left demonstrates the "Particle Residence Time;" the segment (a) shows the anodic workpiece in the yz-plane and the cathodic electrode (not shown) is in the yz-plane toward the positive $x$-direction. The four green points, I, II, III and IV, represent the particle injection locations. The enlarged view of zone $A$ is shown in segment (b), while segment (c) is the side view of segment (b).
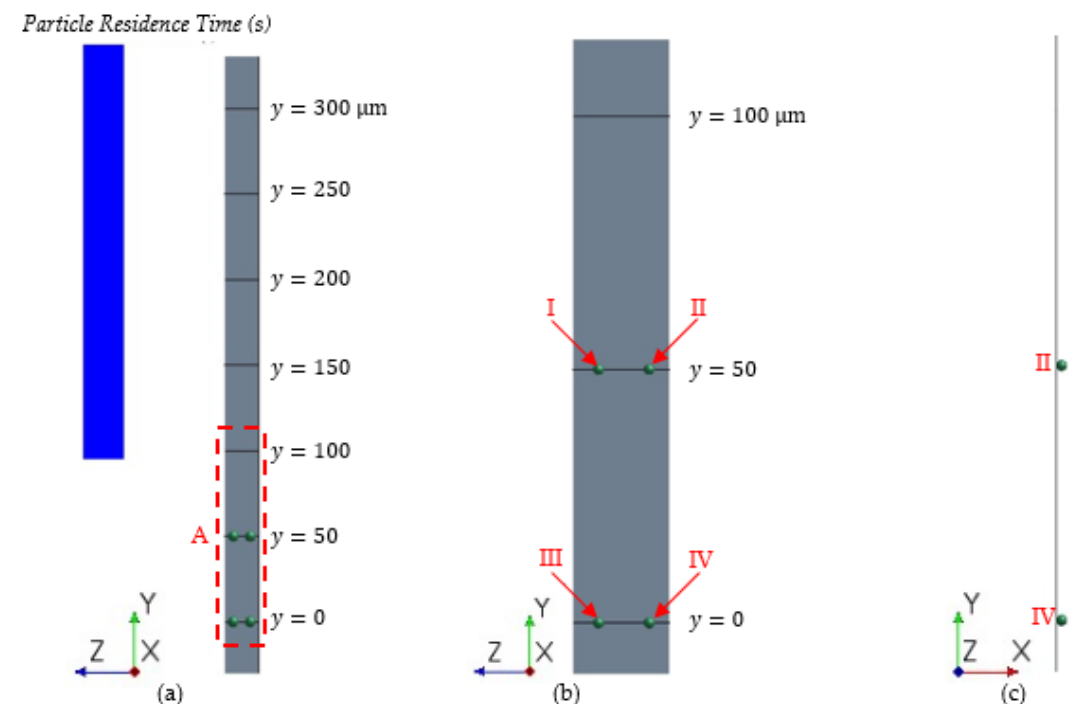

Figure 14 The Star CCM+ simulation results at $\mathrm{t}_{0}=0 \mu \mathrm{s}$.

(a) The workpiece surface in the yz-plane; (b) enlarged view of section A; and (c) side view of (b)

To visualize and follow the motion of a particle at different time and location, define the particle with nomenclature $P_{X, i}\left(t_{j}\right)$ : where $X=I, I I, I I I, I V$ is the particle injection location, $i=1,2,3, \ldots, n$ is the particle injection order, and $j=$ $1,2,3, \ldots, n$ is injection time. For example, the particle $P_{I V, 1}\left(t_{1}\right)$ represents the 1st particle released at location IV and at time $t_{1}$. For simplification, only the right side (locations II \& IV) is presented since there is no interaction of particles releasing from II and IV locations with those released at the I and III locations.

- At time $t_{1}=1 \mu \mathrm{s}$, the particle $P_{I V, 1}\left(t_{1}\right)$ is just released from the anodic plate and it is still in contact with the surface (Figure 15).
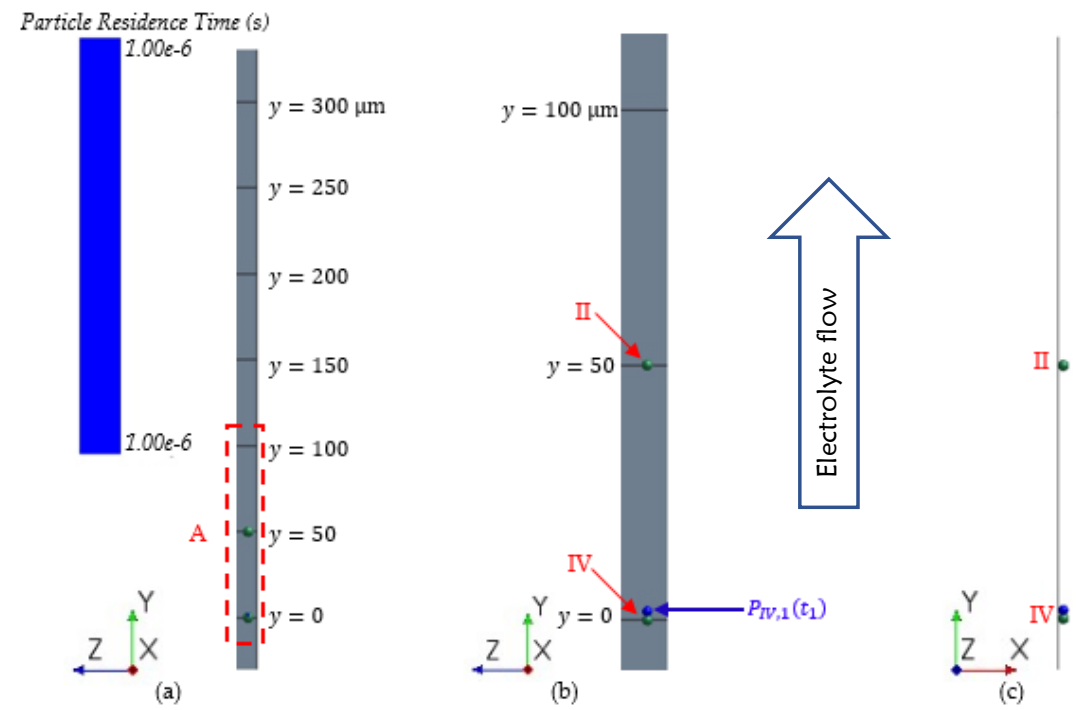

Figure 15 The Star CCM+ simulation results at $\boldsymbol{t}_{\mathbf{1}}=\mathbf{1} \mu \mathrm{s}$. 
The timely release of other particles includes:

- The particle $P_{I V, 2}$ is released into simulation domain at time $t_{2}=71 \mu \mathrm{s}$, represented as $P_{I V, 2}\left(t_{2}\right)$

- Particle $P_{I V, 3}$ at time $t_{3}=81 \mu \mathrm{s}$

- Particle $P_{I I, 4}$ at time $t_{4}=91 \mu \mathrm{s}$

- Particle $P_{I I, 5}$ at time $t_{5}=141 \mu \mathrm{s}$

- Particle $P_{I I, 6}$ at time $t_{6}=151 \mu \mathrm{s}$

- Particle $P_{I I, 7}$ at time $t_{7}=211 \mu \mathrm{s}$

Recall from Figure 2 that the simulation zone is at the top of a workpiece with $300 \mu \mathrm{m}$ zone, and the electrolyte flow is upward along the positive $Y$ axis. Thus, the motion of all particles will be in the upward direction of this horizontal ECM setup.

- $\quad$ At time $t_{7}=211 \mu \mathrm{s}$, the locations of these particles are illustrated in Figure 16.

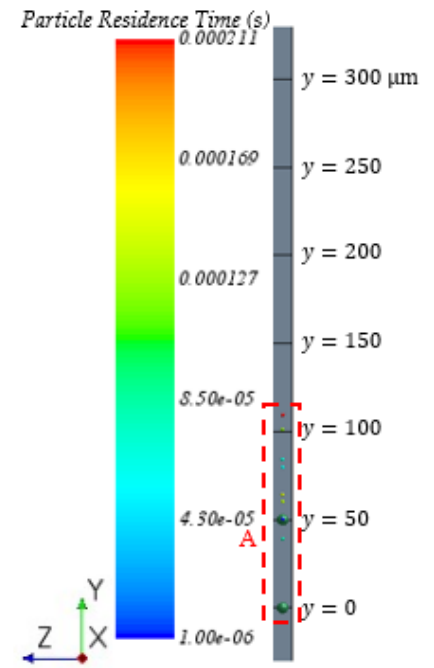

(a)

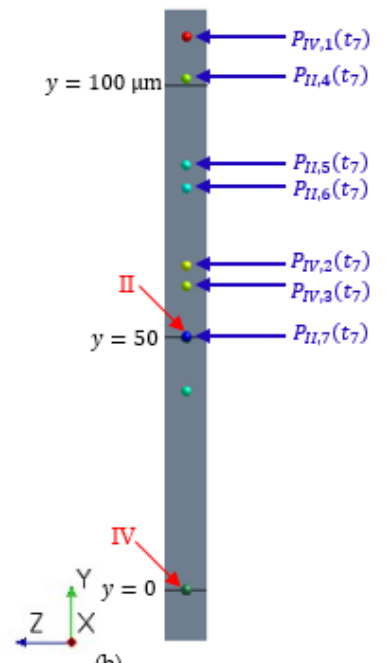

(b)

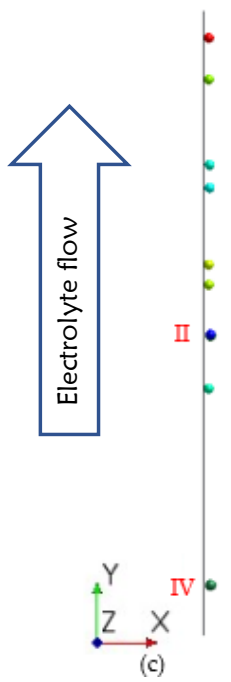

(c)

As simulation continues, there are collisions occur between the particles. Figure 17 and the closed-up Figure 18 illustrate the interaction among particles $P_{I V, 2}, P_{I V, 3}$ and $P_{I I, 7}$.

- At time $t_{8}=272 \mu \mathrm{s}$, the particle $P_{I I, 7}$ impacts the particle $P_{I V, 3}$ (marked with “*”). After collision, this particle $P_{I V, 3}$ obtains an acceleration along the $y$-direction and its flow speed along the $y$-direction is increased. The particle $P_{I I, 7}$ obtains an additional acceleration along the $x$-direction and it moves toward the cathodic electrode (not shown, but on the yz-plane in the positive $x$-direction), while it continues to move along $y$-direction due to the drag effect of the fluid.

- At time $t_{9}=280 \mu \mathrm{s}$, the particle $P_{I V, 3}$ impacts the particle $P_{I V, 2}$. After collision, the particles $P_{I V, 3}$ and $P_{I V, 2}$ will combined and move together. The speed of particle $P_{I I, 7}$ along the $y$-direction is increasing due a higher electrolyte flow speed away from the anodic surface.

- At time $t_{10}=287 \mu \mathrm{s}$, after colliding among particles $P_{I V, 2}, P_{I V, 3}$ and $P_{I I, 7}$, the particle $P_{I I, 7}$ passes the particle $P_{I V, 3}$.

- At time $t_{11}=291 \mu \mathrm{s}$, the particle $P_{I I, 7}$ passes the particle $P_{I V, 2}$, and continue passes the particle $P_{I I, 6}$.

- At time $t_{12}=322 \mu \mathrm{s}$, the particle $P_{I I, 7}$ impacts the particle $P_{I I, 5}$ and continue moves along the $y$-direction.

- At time $t_{13}=353 \mu \mathrm{s}$, the particle $P_{I I, 7}$ has already passed the particle $P_{I V, 1}$. 


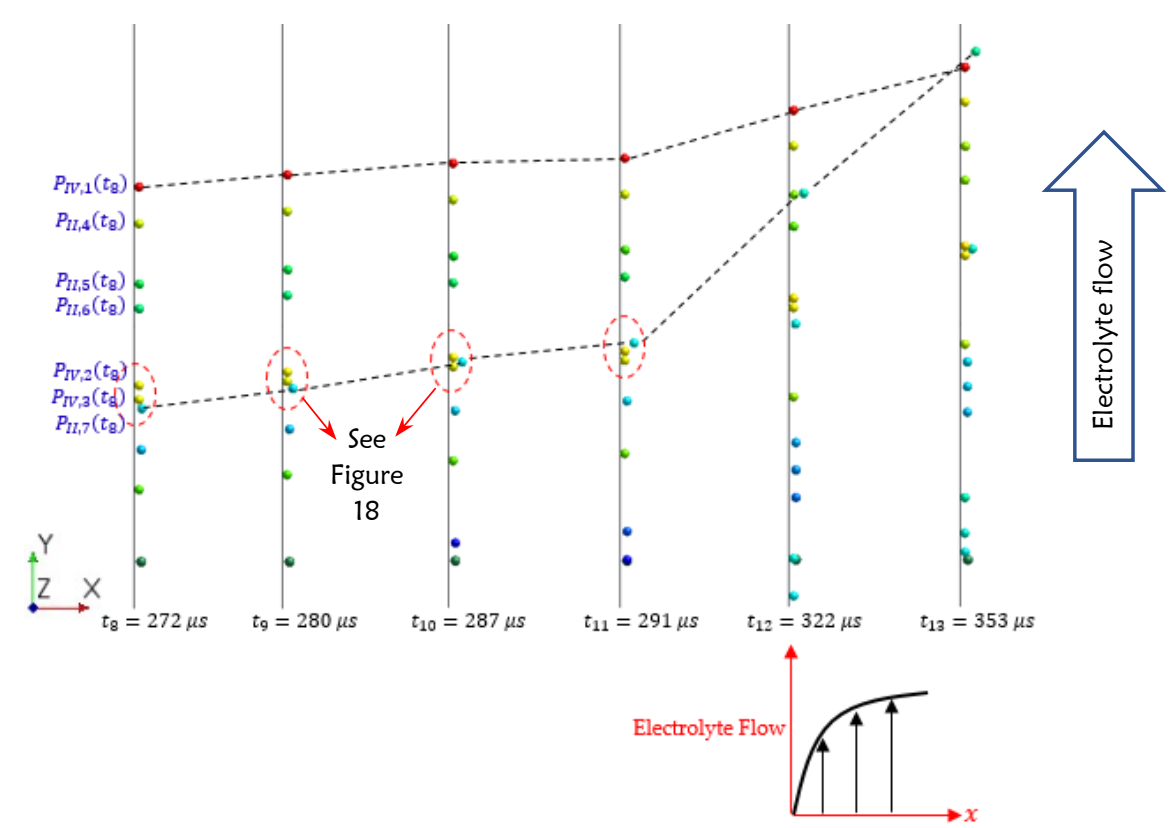

Figure 17 Illustration of particle collisions within zone B from $t_{8}=272 \mu \mathrm{s}$ to $t_{13}=353 \mu \mathrm{s}$.
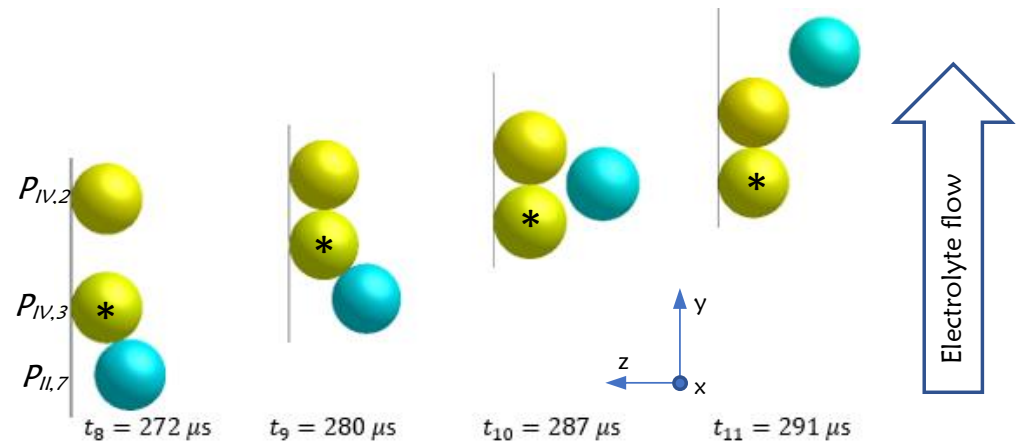

Figure 18 Enlarged view of Figure 17. A “*” is marked on particle $P_{I V, 3}$ for identification purpose.

Figure 19 illustrates the motion of particles $P_{X, 1-6}$ from $t_{14}=512 \mu \mathrm{s}$ to $t_{16}=940 \mu \mathrm{s}$.

- At time $t_{14}=512 \mu \mathrm{s}$, the $y$ coordinate of the particle $P_{I I, 7}$ is larger than $300 \mu \mathrm{m}$, which means that the particle is flushed away from the interested simulation domain.

The particle $P_{I V, 2}$ obtains an acceleration along the y-direction due to a collision and then its speed is larger than that of the particle $P_{I V, 3}$. Hence, these two particles are separated and move independently.

- At time $t_{19}=940 \mu \mathrm{s}$, the $y$-coordinate of the particle $P_{\mathrm{IV}, 1}$ is larger than $300 \mu \mathrm{s}$, as shown in Figure 19 and 20. There is no interaction of particles releasing from II and IV locations with these from I and III locations. Thus, it is reasonable to use the right side of the workpiece to analysis the multiple particles flushing process.

The average flushing speed of the particle $P_{I V, 1}$ is:

$$
V_{\text {ave }}=\frac{\text { total travel distance }}{\text { travel time }}=\frac{300 \mu \mathrm{m}}{940 \mu \mathrm{s}}=0.319 \mathrm{~m} / \mathrm{s}
$$

The average flushing speed, calculated from Star CCM+ $(0.319 \mathrm{~m} / \mathrm{s}$ showing above), agrees with the result calculated from the ANASYS Fluent $(0.396 \mathrm{~m} / \mathrm{s})$ shown in equation (16). 


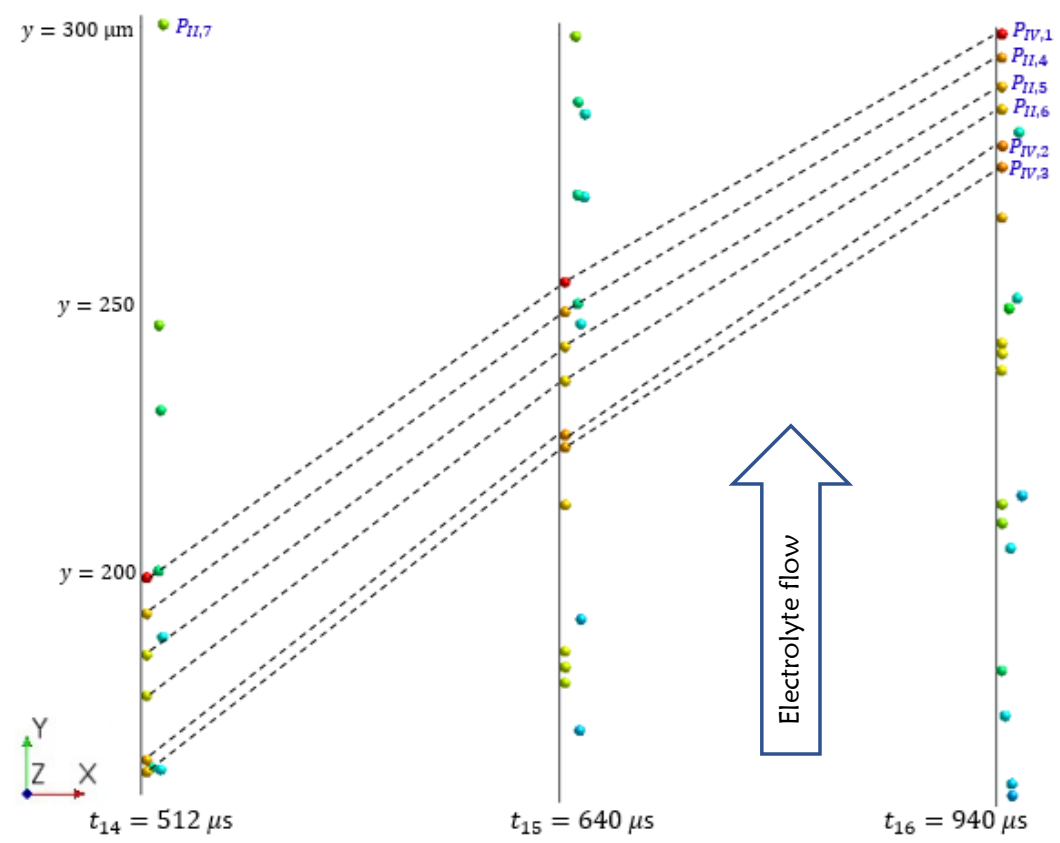

Figure 19 The Star CCM+ simulation results from $t_{14}=512 \mu \mathrm{s}$ to $t_{16}=940 \mu \mathrm{s}$

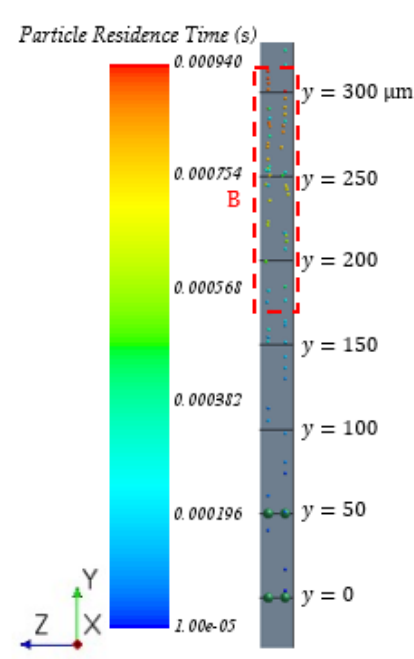

(a)

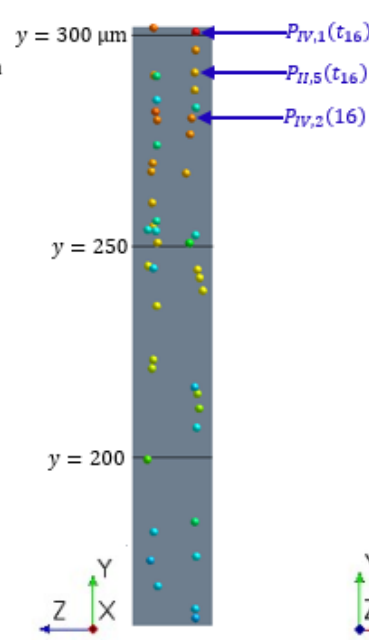

(b)

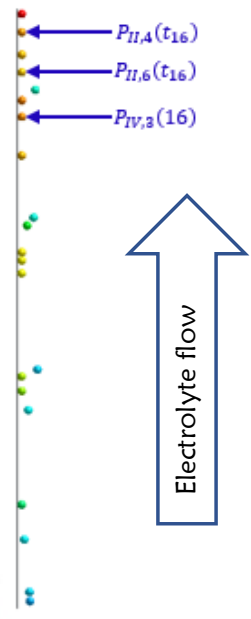

(c)

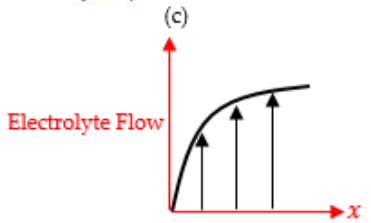

Figure 12 The Star CCM+ simulation results at $t_{16}=940 \mu \mathrm{s}$.

\section{CONCLUSIONS AND RECOMMENDATIONS}

This research used both the ANSYS Fluent and Star CCM+ software to simulate particle transport process within interelectrode gap in the low frequency vibration-assisted electrochemical machining (ECM) process. A series of simulations were conducted to calculate the particle average flushing speed. The study aimed to find relevant process parameters to increase particle flushing speed, therefore, material removal rate and part quality after ECM. This study showed that:

1) Simulations of the motion of a single particle using computational fluid dynamic are performed to track the particle motion and speed between two electrodes. Flushing of the by-products is characterized by 
calculating of particle flushing speed when it exits inter-electrode gap. The maximum flushing speed of $\sim 0.4$ $\mathrm{m} / \mathrm{s}$ was calculated for workpiece vibration frequency of $40 \mathrm{~Hz}$ at $10 \mu \mathrm{m}$ vibration amplitude.

2) Since the particle generating rate is significant smaller than the electrolyte flow rate, it is reasonable to use a single particle for simulation instead of involving multiple particles in the simulation.

3) The simulation results indicate the average flushing speed in ECM would increase with: workpiece vibration frequency, vibration amplitude, electrolyte flow rate, and particle size.

4) The ECM experimental results show that the high flushing speed of by-products would enhance the process since it produces a deeper hole (increasing material removal rate) while forming a sharper hole profiles (increasing product quality).

5) The $2 \mu \mathrm{m}$ spherical particles were used in this study, further study should consider the interactions between different shapes and different size of by-product particles.

\section{REFERENCES}

1. McGeough, J.A. Principles of electrochemical machining. Chapman and Hall: London, 1974.

2. Acharya, B.R.; Mohanty, C.P.; Mahapatra, S.S. Multi-objective optimization of electrochemical machining of hardened steel using NSCAll. Procedia Engineering 2013, 51, 554-560.

3. Bhattacharyya, B.; Sorkhel, S.K. Investigation for controlled electrochemical machining through response surface methodology-based approach. Journal of Materials Processing Technology 1999, 86, 200-207.

4. Senthilkumar, C.; Ganesan, G.; Karthikeyan, R.; Srikanth, S. Modelling and analysis of electrochemical machining of cast al/20\%sicp composites. Materials Science and Technology 2010, 26, 289-296.

5. Schuster, R.; Kirchner, V.; Allongue, P.; Ertl, G. Electrochemical micromachining. Science 2000, 289, 98-101.

6. Feng, Z.; Granda, E.; Hung, W. Experimental investigation of vibration-assisted pulsed electrochemical machining. Procedia Manufacturing 2016, 5, 798-814.

7. Bhattacharyya, B.; Munda, J. Experimental investigation on the influence of electrochemical machining parameters on machining rate and accuracy in micromachining domain. International Journal of Machine Tools and Manufacture 2003, 43, 1301-1310.

8. Munda, J.; Bhattacharyya, B. Investigation into electrochemical micromachining (EMM) through response surface methodology-based approach. The International Journal of Advanced Manufacturing Technology 2008, 35, 821-832.

9. Senthilkumar, C.; Ganesan, G.; Karthikeyan, R. ECM of al/15\% SiCp composites through a response surface methodology-based approach. International Journal of Materials Research 2012, 103, 378-382.

10. Ghoshal, B.; Bhattacharyya, B. Vibration assisted electrochemical micromachining of high aspect ratio micro features. Precision Engineering 2015, 42, 231-241.

11. Ebeid, S.J.; Hewidy, M.S.; El-Taweel, T.A.; Youssef, A.H. Towards higher accuracy for ECM hybridized with low-frequency vibrations using the response surface methodology. Journal of Materials Processing Technology 2004, 149, 432-438.

12. Liu, Z.; Zhang, H.; Chen, H.; Zeng, Y. Investigation of material removal rate in micro electrochemical machining with lower frequency vibration on workpiece. International Journal of Machining and Machinability of Materials 2013, 14, 91-104.

13. Bhattacharyya, B.; Malapati, M.; Munda, J.; Sarkar, A. Influence of tool vibration on machining performance in electrochemical micro-machining of copper. International Journal of Machine Tools and Manufacture 2007. 47, 335-342.

14. Rebschläger, A.; Kollmannsperger, R.; Bähre, D. Video based process observations of the pulse electrochemical machining process at high current densities and small gaps. Procedia CIRP2014, 14, 418-423.

15. Ruszaj, A.; Zybura-Skrabalak, M.; Skoczypiec, S.; Żurek, R. In Electrochemical machining supported by electrode ultrasonic vibrations, 13th International Symposium for Electromachining, ISEM, Spain, May, 2001; pp 9-11.

16. Patel, J.B.; Feng, Z.; Villanueva, P.; Hung, W.N.P. Quality enhancement with ultrasonic wave and pulsed current electrochemical machining. Procedia Manufacturing 2017, 10, 662-673.

17. Pa, P.S. Electrode form design of large holes of die material in ultrasonic electrochemical finishing. Journal of Materials Processing Technology 2007, 192-193, 470-477.

18. Skoczypiec, S. Research on ultrasonically assisted electrochemical machining process. The International Journal of Advanced Manufacturing Technology 2010, 52, 565-574.

19. Feng, Z.; Izwan, N.S.L.B.; Gutierrez, E.E.G.; Hung, W. In Energy comparative study for mechanical punching, electrical-discharge machining and electro-chemical machining, 5th International Welding, Industrial Engineering and Manufacturing Congress, Saltillo, Coahuila, Mexico, 2015; Saltillo, Coahuila, Mexico.

20. Feng, Z.; Orona-Hinojos, J.M.; Villanueva, P.P.; Lomeli, P.; Hung, W.N.P. Flushing enhancement with vibration and pulsed current in electrochemical machining. International Journal of Engineering Materials and Manufacture 2017, 2, 67-85.

21. Feng, Z.; Patel, J.; Granda, E. Process selection for energy efficiency. In American Society for Engineering and Education (ASEE) conference, Seattle, Washington, USA, 2015. 
22. Rajurkar, K.P.; Sundaram, M.M.; Malshe, A.P. Review of electrochemical and electrodischarge machining. Procedia CIRP 2013, 6, 13-26.

23. Deconinck, D.; Damme, S.V.; Deconinck, J. A temperature dependent multi-ion model for time accurate numerical simulation of the electrochemical machining process. Part ii: Numerical simulation. Electrochimica Acta 2012, 69, 120-127.

24. Deconinck, D.; Van Damme, S.; Deconinck, J. A temperature dependent multi-ion model for time accurate numerical simulation of the electrochemical machining process. Part i: Theoretical basis. Electrochimica Acta 2012, 60, 321-328.

25. Alder, G.M.; Clifton, D.; Mill, F. A direct analytical solution to the tool design problem in electrochemical machining under steady state conditions. Proceedings of the Institution of Mechanical Engineers, Part B: Journal of Engineering Manufacture 2000, 214, 745-750.

26. Prentice, G.A.; Tobias, C.W. Simulation of changing electrode profiles. Journal of The Electrochemical Society 1982, 129, 78-85.

27. Moarrefzadeh, A. Finite-element simulation of dimensional limitation of ECM process. International Journal of Multidisciplinary Sciences and Engineering 2011, 2, 39-43.

28. Purcar, M.; Bortels, L.; Van den Bossche, B.; Deconinck, J. 3d electrochemical machining computer simulations. Journal of Materials Processing Technology 2004, 149, 472-478.

29. Kozak, J.; Gulbinowicz, D.; Gulbinowicz, Z. The mathematical modeling and computer simulation of pulse electrochemical micromachining. Engineering Letters 2008, 16, 556-561.

30. Bortels, L.; Purcar, M.; Bossche, B.V.d.; Deconinck, J. A user-friendly simulation software tool for 3D ECM. Journal of Materials Processing Technology 2004, 149, 486-492.

31. Volgin, V.M.; Davydov, A.D. Mass-transfer problems in the electrochemical systems. Russian Journal of Electrochemistry 2012, 48, 565-569.

32. Minazetdinov, N.M. A hydrodynamic interpretation of a problem in the theory of the dimensional electrochemical machining of metals. Journal of Applied Mathematics and Mechanics 2009, 73, 41-47.

33. Minazetdinov, N.M. A scheme for the electrochemical machining of metals by a cathode tool with a curvilinear part of the boundary. Journal of Applied Mathematics and Mechanics 2009, 73, 592-598.

34. Ma, N.; Xu, W.; Wang, X.; Tao, B. Pulse electrochemical finishing: Modeling and experiment. Journal of Materials Processing Technology 2010, 210, 852-857.

35. Wu, J.; Wang, H.; Chen, X.; Cheng, P.; Ding, G.; Zhao, X.; Huang, Y. Study of a novel cathode tool structure for improving heat removal in electrochemical micro-machining. Electrochimica Acta 2012, 75, 94-100.

36. Zhu, H.P.; Zhou, Z.Y.; Yang, R.Y.; Yu, A.B. Discrete particle simulation of particulate systems: Theoretical developments. Chemical Engineering Science 2007, 62, 3378-3396.

37. Xiong, Y.; Zhang, M.; Yuan, Z. Three-dimensional numerical simulation method for gas-solid injector. Powder technology 2005, 160, 180-189.

38. Li, Y.; Zhang, J.; Fan, L.-S. Numerical simulation of gas-liquid-solid fluidization systems using a combined CFD-VoF-DPM method: Bubble wake behavior. Chemical Engineering Science 1999, 54, 5101-5107.

39. Richardson, J. Incipient fluidization and particulate systems. American Press, London: 1971; pp 27-29.

40. Ergun, S.; Orning, A.A. Fluid flow through randomly packed columns and fluidized beds. Industrial \& Engineering Chemistry 1949, 41, 1179-1184.

41. Choi, H.G.; Joseph, D.D. Fluidization by lift of 300 circular particles in plane poiseuille flow by direct numerical simulation. Journal of Fluid Mechanics 2001, 438, 101-128.

42. Li, J.; Kwauk, M. Exploring complex systems in chemical engineering-the multi-scale methodology. Chemical Engineering Science 2003, 58, 521-535.

43. Morsi, S.; Alexander, A. An investigation of particle trajectories in two-phase flow systems. Journal of Fluid mechanics 1972, 55, 193-208.

44. Tsuji, Y.; Kawaguchi, T.; Tanaka, T. Discrete particle simulation of two-dimensional fluidized bed. Powder Technology 1993, 77, 79-87. 